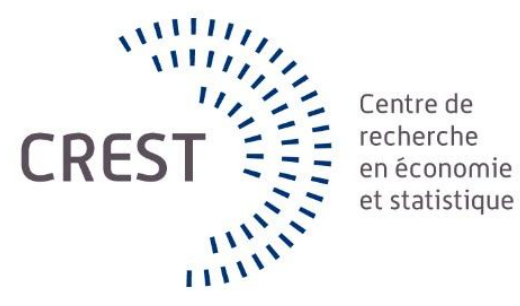

Série des Documents de Travail

\author{
$n^{\circ}$ 2014-35 \\ Selection in Tournaments: \\ The Case of Chess Players \\ L. LINNEMER \\ M. VISSER ${ }^{2}$
}

Les documents de travail ne reflètent pas la position du CREST et n'engagent que leurs auteurs. Working papers do not reflect the position of CREST but only the views of the authors.

\footnotetext{
${ }^{1}$ CREST (LEI), e-mail : laurent.linnemer@ensae.fr.

${ }^{2}$ CREST (LEI) and CRED, University of Paris 2.
} 


\title{
Selection in Tournaments: The Case of Chess Players*
}

\author{
Laurent Linnemer ${ }^{\dagger}$ and Michael Visser ${ }^{\ddagger}$
}

December 2014

\begin{abstract}
We consider a simple tournament model in which individuals auto-select into the contest on the basis of their commonly known strength levels, and privately observed strengthshocks (reflecting temporary deviations from observed levels). The model predicts that the participation rate should increase with the player's observed strength, and the total awarded prize amount. Furthermore, under certain conditions self-selection implies that participants with high observed strength levels have smaller expected strength-shocks than those with low levels. Consequently, the latter should play better than predicted and the former worse (given their observed strength). These predictions are confronted with data from a large chess tournament held in the USA. This tournament is divided into different sections, with players being able to play in the section to which their current chess rating (observed strength) belongs. As predicted, we find that within each section the participation probability increases with chess rating and prize amounts, and players with a relatively low (resp. high) rating are indeed the ones who have a better (resp. worse) relative performance.
\end{abstract}

Keywords: Chess, Prizes, Relative Performance, Selection, Sorting, Tournament

JEL codes: D820 L830

\footnotetext{
${ }^{*}$ We thank Pierre-André Chiappori, Philippe Choné, Pascal Courty, Xavier D'Haultfoeuille, Phillip Wichardt, Lionel Wilner, and seminar participants at the 2013 CESifo Conference on Applied Microeconomics in Munich, Rostock University, and the 2013 EARIE conference in Evora, for helpful comments. We also thank Matthieu Bizien and Philippe Donnay for excellent research assistance. Financial support from the LABEX ECODEC is gratefully acknowledged.

${ }^{\dagger}$ CREST (LEI), 15 bd Gabriel Péri, 92245 Malakoff cedex, France. Please address correspondence to Laurent Linnemer, laurent.linnemer@ensae.fr.

${ }^{\ddagger}$ CREST (LEI) and CRED, University of Paris 2.
} 


\section{Introduction}

Incentive pay schemes are designed to induce more effort from workers and also to attract the most productive employees. Various types of pay schemes are used in practice to achieve these two goals. In economic sectors where output is individual-specific and easily observable and measurable, firms often pay piece-rate wages to their employees. Workers' salaries are then directly linked to their realized production levels, creating the incentives for them to exert optimal effort levels. It is also thought that such a compensation arrangement is primarily attractive to the most efficient workers. Lazear (2000), for instance, analyzes data from a firm in which the management modified the method of compensating workers from hourly wages to piece-rate pay, and documents patterns of self-selection among the employees of this firm: the less productive workers left the firm after the change in payment policy, and more productive ones got hired.

The compensation structure adopted in rank-order tournaments is another example of an incentive pay scheme. In a tournament, workers are paid according to their final ranking in the competition: the best performing worker receives the first prize, the one ending second the second highest award, and so forth. They are in this case rewarded according to their relative performances (and not on the basis of absolute performances as in the piece-rate example). Real-life applications of rank-order tournaments abound: salesmen with the highest sales figures get end-of-year bonuses, the most prolific associate professors are promoted to full professorship, and junior lawyers who win most cases are offered a partnership in law firms.

While there is an abundant literature on the incentive effects of tournaments, ${ }^{1}$ there are only a few papers which have studied tournament-participation decisions, and the possible consequences of self-selection on the outcomes of the competition. Stein (2002) characterizes the Nash equilibrium efforts in a contest between heterogenous players. In particular, he finds which players are active at the Nash equilibrium. Inactive players (zero effort) can thus be seen as staying out of the tournament. Myerson and Wärneryd (2006) study contests where the set of players is a random variable. ${ }^{2}$ In an empirical paper, Brown (2011) shows that golf players perform less well when a superstar (Tiger Woods) participates in the tournament, thereby suggesting that the precise composition of the pool of participants may influence players' performances, which in turn affects the outcome of the contest itself. There are also a few papers focussing on the case where agents have the possibility to choose between multiple tournaments. Leuven, Oosterbeek, Sonnemans, and van der Klaauw (2011) report the results of a field experiment in which students of microeconomics at the University of Amsterdam could auto-select themselves into one of three tournaments. ${ }^{3}$ These data allowed the authors to disentangle the effects of prizes and self-selection on exam grades. They find that the observed increment in grades (across the three treatment groups) is not due to increased effort of students but to sorting of more able students to tournaments with higher awards. Azmat and Möller (2009) study professional road runners who can choose between contests differing in race-distance and prize structure. They find, among other things, that in long races, steeper prizes (more unequal prizes) increase the participation of top runners, while there is no such

\footnotetext{
${ }^{1}$ For early theoretical contributions see for instance Lazear and Rosen (1981), Green and Stokey (1983), Nalebuff and Stiglitz (1983), and Moldovanu and Sela (2001), and a recent survey Konrad (2009). For empirical contributions Ehrenberg and Bognanno (1990), Eriksson (1999), and Coffey and Maloney (2010).

${ }^{2}$ That is, each player is randomly selected in (or out of) the tournament and exerts effort not knowing how many other players are in. Players are otherwise symmetric. Comparing total effort in a contest with an uncertain number of players (with $\mu$ players on average) with a contest with no uncertainty and exactly $\mu$ players, they show that aggregate effort is larger without uncertainty.

${ }^{3}$ Each student within a tournament was randomly allocated to a treatment and control group. Those in the treatment group of a given tournament could compete for a prize awarded (prizes differed across the three tournaments) to the student with the highest exam grade.
} 
link in medium and short races. This result is compatible with the authors' theoretic model in which runners' contest choice depends on the prize structure and on how sensitive a contest's outcome is with respect to individual efforts. ${ }^{4}$

Our paper contributes to this literature. Using data from the World Open Chess tournament (a large chess competition held in the USA each year), we analyze which players decide to participate, and how this participation decision varies with the level of awarded prizes. ${ }^{5} \mathrm{We}$ also study how players, conditional on their decision to participate, perform in the contest. We find that players with higher chess ratings are more likely to participate, and this effect is magnified when prize budgets increase. More surprisingly, we also observe that highly rated participants under-perform while the lowly rated ones over-perform. Our explanation for this phenomenon follows from a simple participation model in which players self-select on their unobservable chess-strength shocks.

We have twelve years of data from the World Open chess tournament. It is open to professional and amateur players of all levels. To acknowledge the differences in strength between players, the tournament is divided into sub-tournaments, or sections. Each section is defined as an Elo-rating interval (the Elo rating system was introduced by Elo (1978) and is since the 1970s used by all chess federations throughout the world), and chess players can participate in the section to which their Elo rating belongs. Players within a given section compete with each other and the best ranked ones at the end of the tournament win prizes. The prizes awarded in the World Open are very high, and this should create the necessary incentives for the chess participants to play as well as they can. Self-selection is also expected to play a role as players with an Elo rating near the top of their section have (all other things equal) a higher chance to win than those near the bottom. Another reason to suspect self-selection in the data is that optimal chess performance requires a serious preparation (through studying openings for instance) and a 'well-rested brain'. Chess players who have prepared intensively just before the tournament and who have been through a calm and stress-less period are thus expected to participate relatively more.

The data set records all match outcomes, all scores (after each round and at the end of the tournament), the Elo rating of each player, some other player characteristics (state of origin, chess history prior to the tournament, etc.), and the prize winners. An originality of our data set is that we observe for each year the whole population of potential participants (i.e., all individuals registered with the US chess federation). This allows us to study the determinants of tournament participation.

The data are confronted with several predictions that we derive from a simple model of tournament-entry. In this model a chess player is assumed to participate in the tournament if the expected prize amount plus the net private benefit from playing exceeds the average cost of participation (registration fee plus average travel and lodging expenses). The expected prize amount depends on the commonly observed player-strength (measured by the Elo rating) and a privately observed strength-shock, which captures the fact that actual strength may slightly deviate from the Elo rating (because of a bad or good preparation, or because of having experienced a busy or calm period). Players auto-select into the tournament on the basis of their observed strength, their unobserved strength shock, and their unobserved net private benefit. A first prediction is that players with a rating near the top of their section should participate more than those with a rating near the bottom, and that this effect should

\footnotetext{
${ }^{4}$ See for other theoretical papers on optimal contest choice Damiano, Hao, and Suen (2010) and Damiano, Hao, and Suen (2012).

${ }^{5}$ Several recent papers have studied data on chess players and competitions: Moul and Nye (2009), Gerdes and Gränsmark (2010), Levitt, List, and Sadoff (2011), Gränsmark (2012), and Dreber, Gerdes, and Gränsmark (2013). None of these papers has explicitly studied the issue of selection in tournaments and its consequences on performance.
} 
be amplified when prizes are higher. We test this by running a logit model of a participation indicator on the Elo rating (and various control variables), and find that the results are in line with theory.

A second prediction follows from the fact that, under certain conditions on the distribution of strength shocks and net benefits, the expected strength-shock should be decreasing with the Elo rating of participants. The difference between real chess strength (measured as the sum of the Elo rating and the strength shock) and the observed strength (Elo rating) is then, on average, larger among lowly rated players than among highly rated players. Our second prediction is therefore that, if there is indeed auto-selection on unobserved strength shocks, the expected outcome of a chess match is not well measured by the so-called Elo winning expectancy formula, which gives the expected match outcome on the basis of the two players' Elo ratings alone. ${ }^{6}$ For instance, when a highly rated player confronts a lowly rated player, the expected outcome should be inferior to what is given by Elo's formula. To test the second prediction, we regress match outcomes on a function of each player's Elo rating that encompasses the Elo formula as a special case, and check whether the parameters in the model equal certain specific values. We find again that the results are in line with theory: when lowly rated players confront highly rated players, the former perform indeed better than predicted (by Elo's formula) than the latter.

As a robustness check, we also analyze data from the Paris Chess Tournament. The setup of this chess contest is quite similar to the World Open except that prizes are substantially lower (prizes in the Paris tournament are about one tenth of the prizes awarded in the US). The expected prize amount should then be a flatter function of the player's observed strength, implying that the average difference between real and observed strengths across different types of players should be smaller, which in turn implies that the auto-selection on strength shocks should be a less relevant phenomenon. This is confirmed in the data since we find that Elo's winning expectancy formula fits the expected game outcomes quite adequately.

The paper is organized as follows. Section 2 gives background information about the World Open chess tournament, and Section 3 about the Elo rating system. Section 4 explains how the data set is constructed, and Section 5 describes all available variables. Section 6 presents our model of tournament entry and its predictions, Section 7 the main results, and Section 8 the robustness analysis. Finally, Section 9 concludes.

\section{The World Open chess tournament}

The World Open chess tournament (hereafter World Open) is the largest chess tournament in the world both in terms of prize levels and number of participants. It is held every year in the U.S., around the 4th of July week-end, and is organized by the Continental Chess Association (CCA). The first World Open took place in New York City in 1973, and since 1977 it has been organized in Pennsylvania (in either King of Prussia or Philadelphia). ${ }^{7}$ In 1973 there were just two sections: a so-called Open section (open to all players regardless of their chess levels) and a Booster section (where only those with a rating below 1,800 could play). In that year, a total of 725 players attended the tournament (369 in the Open and 356 in the Booster). In 1977 the

\footnotetext{
${ }^{6}$ Since the 1960s, Elo's formula is used by chess federations throughout the world to predict game outcomes and update chess ratings of players given their results in competitions or tournaments.

${ }^{7}$ A detailed description of the early years (1973-1991) does not seem to exist. A Wikipedia page (http:// en.wikipedia.org/wiki/World_Open_chess_tournament) gives, however, some information on the tournament winners in those years together with their scores, precise tournament locations and dates, and attributed prizes. For the period 1992-2012 more detailed information is available on the U.S. Chess Federation (USCF) webpages (http://www.uschess.org/), and for the period 2001-2012 precise statistics on prizes can be found on CCA's website (http://www. chesstour.com/).
} 
organizers decided to increase the number of sections to eight and since then this number has varied from year to year, down to five in 1983 and up to eleven in 2008. The Open section was always maintained, and over time it has become almost exclusively a section for professional players (broadly defined as players with a rating above 2,400). The other sections were by definition reserved for amateur players. By increasing the number of sections for amateurs, the CCA wanted to avoid matches that were too unbalanced, i.e., matches between players with large differences in chess strengths.

Table 1 shows the number of participants for each World Open section from 2001 to 2012, the time period for which we were able to collect complete data on all game results as well as all awarded prizes. The amateur sections are denoted U2400 (meaning "under 2,400", for players with ranking below 2,400 only), U2200 ("under 2,200", for players ranked below 2,200 only), ..., U600 ("under 600", for players ranked below 600 only). During the period of observation the number of sections and the delimitation of each section have been quite stable. The main novelty was the introduction in 2007 of the U2400 section, placed between the Open and U2200 sections. Also, on several occasions, some sections were momentarily dropped while others were introduced: For instance, in 2011, U1400 was dropped and was replaced by U1300; in 2007, U1200 was dropped while U1100 and U800 were added.

Table 1: Number of players by year and section

\begin{tabular}{|c|c|c|c|c|c|c|c|c|c|c|c|c|c|c|}
\hline Year & Open & U2400 & U2200 & U2000 & U1800 & U1600 & U1400 & U1300 & U1200 & U1100 & U900 & U800 & U600 & Total \\
\hline 2001 & 228 & 0 & 158 & 192 & 224 & 230 & 166 & 0 & 116 & 0 & 0 & 0 & 0 & 1,314 \\
\hline 2002 & 217 & 0 & 164 & 224 & 249 & 218 & 157 & 0 & 90 & 0 & 0 & 0 & 0 & 1,319 \\
\hline 2003 & 240 & 0 & 176 & 245 & 256 & 226 & 146 & 0 & 130 & 0 & 0 & 0 & 0 & 1,419 \\
\hline 2004 & 234 & 0 & 175 & 206 & 237 & 213 & 137 & 0 & 102 & 0 & 0 & 0 & 0 & 1,304 \\
\hline 2005 & 205 & 0 & 136 & 200 & 198 & 173 & 99 & 0 & 95 & 0 & 0 & 0 & 0 & 1,106 \\
\hline 2006 & 237 & 0 & 202 & 279 & 224 & 244 & 143 & 0 & 132 & 0 & 0 & 0 & 0 & 1,461 \\
\hline 2007 & 92 & 131 & 170 & 236 & 217 & 157 & 143 & 0 & 0 & 52 & 0 & 30 & 0 & 1,228 \\
\hline 2008 & 118 & 128 & 193 & 218 & 236 & 185 & 127 & 0 & 99 & 0 & 45 & 0 & 28 & 1,377 \\
\hline 2009 & 98 & 129 & 186 & 225 & 212 & 169 & 128 & 0 & 81 & 0 & 121 & 0 & 0 & 1,349 \\
\hline 2010 & 119 & 121 & 158 & 200 & 179 & 139 & 87 & 0 & 78 & 0 & 65 & 0 & 0 & 1,146 \\
\hline 2011 & 94 & 139 & 177 & 205 & 170 & 209 & 0 & 123 & 0 & 0 & 0 & 0 & 0 & 1,117 \\
\hline 2012 & 118 & 113 & 184 & 234 & 179 & 145 & 103 & 0 & 96 & 0 & 88 & 0 & 0 & 1,260 \\
\hline Total & 2,000 & 761 & 2,079 & 2,664 & 2,581 & 2,308 & 1,436 & 123 & 1,019 & 52 & 319 & 30 & 28 & 15,400 \\
\hline
\end{tabular}

In this paper we focus on four sections: U2200, U2000, U1800, and U1600. We have three main reasons for this choice: i) These sections have existed during the whole observation period; ii) In each given year, their prize structures (number of awarded prizes, amounts) are practically the same; iii) Professional players (ranking above 2,400), and those in the fuzzy zone between very strong amateurs and professionals (2,200-2,400 range), are not allowed to play in them. The fact that the selected sections exist throughout the sample period and have similar prize structures facilitates comparisons across different chess levels and time periods. We have decided to drop (semi) professionals from the analysis as their tournament behavior and motivation to participate are different from the behavior and motivation of amateurs. ${ }^{8}$

The World Open is organized as a nine-round Swiss tournament, meaning that all players have the right to play nine games regardless of their results. In practice players may quit the

\footnotetext{
${ }^{8}$ Many empirical papers studying sports tournaments (see, for example, Ehrenberg and Bognanno (1990)) have deliberately focussed on professional players, arguing that prizes for professionals are much higher than for amateurs, thereby providing the necessary incentives primarily for the former. In the World Open tournaments this argument does not really hold as prize levels are not that much higher for professionals. For instance, in 2005 , the winner of the Open section received $\$ 14,000$, while each winner of our four selected amateur sections received $\$ 10,000$.
} 
tournament at any time (after just one game, two games, etc.), but most do indeed play all nine games. A chess game between two players has three possible outcomes: Player 1 wins (player 1 then gets one point, player 2 zero), player 2 wins (player 2 gets one point, player 1 zero), players 1 and 2 draw (both get half a point). In a Swiss tournament players are matched to each other in the different rounds in a specific way. In the first round, matching is according to players' initial chess ratings (as measured at the beginning of the tournament): the highest rated player of a given section is opposed to the lowest rated player, the second-highest rated player is opposed to the second-lowest rated player, and so on. Matching in subsequent rounds depends on intermediate scores. In round 2 , for instance, players with one point (i.e., who won in round 1) compete with other players who have one point, players with half a point (their first game ended in a draw) are opposed to other players with half a point, and players with zero points (those who lost in round 1) face other players with zero points. The winner of a given section is simply the player who accumulated most points at the end of a tournament (hence there are multiple winners if several players end up with exactly the same number of total points).

\section{Elo rating}

\subsection{Measuring chess strength and updating ratings}

The strength of chess players is measured by a rating method developed in the late 1950s by Arpad Elo, who was a professor of physics at Marquette University, and chairman of the USCF Rating Committee between 1959 and 1976. Since 1970 the Elo rating system has been adopted by the FIDE (Fédération Internationale Des Échecs), the world chess federation founded in 1924 in Paris, and even earlier by the U.S.C.F. Despite its shortcomings, the method is regarded by many experts as functioning reasonably well (Glickman (1995)). ${ }^{9}$

In March 2013, the highest rated player in the world was Magnus Carlsen, a 22 year old Norwegian with a FIDE rating of 2,872, an all-time record. Professional players and master level players are nowadays usually rated by the FIDE (along with their national federation), whereas amateur players are usually only rated by their national federation. To get an idea of the underlying meaning of Elo ratings ${ }^{10}$ it is useful to consider the classification of chess players adopted by the U.S.C.F.: a player with a rating above 2,400 is called a Life Senior Master, a player rated between 2,200 and 2,400 a Life Master, between 2,000 and 2,200 a Candidate Master, between 1,800 and 2,000 a First Category, between 1,600 and 1,800 a Second Category, between 1,400 and 1,600 a Third Category, and below 1,400 a Fourth Category. Note that the sectioning chosen by the World Open organizers closely follows this official U.S.C.F. classification.

An important role in the rating method is played by the so-called Elo formula which gives the expected outcome of a chess game as a function of both players' Elo ratings. To illustrate the formula, consider two good chess players, Alice and Bob. The rating of Alice, denoted $R_{A}$, is equal to 2,050, and the rating of Bob, $R_{B}$, is 1,970. Alice is slightly stronger than Bob and she is expected to win more often when they play one another. The assumption made by Elo is that the winning expectancy only depends on the difference between the two players' ratings. From Alice's point of view the formula for the expected outcome is

$$
\mathrm{WE}_{\mathrm{AB}}=\operatorname{Pr}(\mathrm{A} \text { wins })+0.5 \operatorname{Pr}(\mathrm{A} \text { draws })=\left(1+10^{-\left(\mathrm{R}_{\mathrm{A}}-\mathrm{R}_{\mathrm{B}}\right) / 400}\right)^{-1} .
$$

\footnotetext{
${ }^{9}$ Mark Glickman is the current chairman of the USCF Rating Committee (a position he has held since 1992).

${ }^{10}$ See also page 18 of Elo's book (Elo (1978)).
} 
Given the values of the two ratings, Alice has a winning expectancy equal to $\mathrm{WE}_{\mathrm{AB}}=0.57$. If these two players were to play a match of 100 games, Alice would win on average by 57 points to 43. If, however, Alice were to play against Carlsen, her winning expectancy would only be 0.009: on average she would score almost 1 point out of 100 games, i.e., Alice would not stand a chance against Carlsen. The division of the World Open into different sections is implemented by the CCA precisely to avoid such unbalanced confrontations. Indeed, if Alice joins the U2200 section (the lowest section she is allowed to enter) her strongest possible opponent would be rated 2,199. Although this rating is well above her own, Alice's winning expectancy against such a player would nonetheless be roughly 0.3 points higher than in a match against Carlsen. Bob, on the other, although less highly rated than Alice, is in fact in a better situation. Indeed, he can enter the U2000 section, where he is among the "top rated" players. In the worst case, Bob plays against a 1,999 rated player with a winning expectancy of 0.46 . On the other hand he can play against a player rated as low as 1,800 with a winning expectancy of 0.73 .

The winning expectancy formula is used in updating Elo ratings of players who have participated in competitions or tournaments. Letting $\mathrm{R}_{i}^{\text {before }}$ be player $i$ 's rating before a tournament and $n_{i}$ the number of games played by $i$, the rating after the tournament, denoted $\mathrm{R}_{i}^{\text {after }}$, is computed in the following way:

$$
\mathrm{R}_{i}^{\mathrm{after}}-\mathrm{R}_{i}^{\text {before }}=K_{i} \sum_{t=1}^{n_{i}}(\operatorname{Res}_{i j(t)}-\underbrace{\left(1+10^{\frac{\mathrm{R}_{j(t)}^{\text {before }}-\mathrm{R}_{i}^{\text {before }}}{400}}\right)^{-1}}_{\mathrm{WE}_{i j(t)}})
$$

where $j(t)$ is the identity of $i$ 's opponent in round $t$ of the tournament, $\operatorname{Res}_{i j(t)}$ the outcome of the match between $i$ and $j(t)$ (it equals 1 if $i$ wins, 0 if $i$ loses, and 0.5 in case of a draw), $\mathrm{WE}_{i j(t)}$ the winning expectation of $i$ playing against $j(t)$, and $K_{i}$ an adjustment factor. So according to this formula, updating a player's rating consists in multiplying the sum of deviations between actual and expected match outcomes by the adjustment factor. The precise formula of the factor is not the same for all chess federations. ${ }^{11}$

In our empirical analysis below we will sometimes need to compare results from different sections, or pool data across sections. For this purpose it is useful to define a normalized rating, defined as a player's Elo rating minus the lower bound of the section wherein this player participates. For player $i$ the normalized rating is thus ${ }^{12}$

$$
\mathrm{r}_{i}=\mathrm{R}_{i} \text { - lower bound of the section wherein } i \text { plays. }
$$

Continuing our example, if Alice plays in U2200, her normalized ranking would be $r_{A}=\mathrm{R}_{\mathrm{A}}-$ $2,000=50$, and if Bob plays in U2000 then $r_{B}=R_{B}-1,800=170$.

\footnotetext{
${ }^{11}$ The FIDE defines $K$ as a simple decreasing function of the player's seniority: $K=30$ for a newly registered player, and switches to $K=15$ once 30 officials games have been played; the factor remains fixed at this value as long as the player's rating is below 2,400, and permanently switches to $K=10$ once this threshold is exceeded. The USCF adopts a slightly different formula for $K$ which allows for a larger variation for players with a rating below 2,200:

$$
K_{i}=800 /\left(n_{i}+\min \left\{N_{i} ; 50 / \sqrt{1+\left(\left(2,200-\mathrm{R}_{i}^{\text {before }}\right) / 1,000\right)^{2}}\right\}\right)
$$

where $N_{i}$ is the total number of rated games played by $i$ in the past (before tournament under consideration), and $n_{i}$ the number of games during the tournament. In both the FIDE and the USCF formulae, $K$ captures the volatility or uncertainty of players' strength. In practice it makes the rating of relatively new (or with a relatively low rating in the case of the USCF) players to change more quickly (upwards or downwards). Notice that due to the asymmetry of the factor $K$ between players, the sum of all rating gains during a chess tournament is not necessarily zero.

${ }^{12}$ In 2011 the U1400 section was replaced by the U1300 section. Consequently, for all players who played in U1600 in that year the normalization is: $200 \times(\mathrm{R}-1,300) / 300$.
} 


\subsection{Reference and tournament ratings}

Two specific values of each player's Elo rating are particularly important. First, there is the rating used by the tournament organizers to decide in which section each player can register. We call this rating the reference rating. Before 2008, the reference rating is the June USCF rating. For 2008 and thereafter, it is the July USCF rating. Second, each player has what we call a tournament rating, i.e., the actual Elo rating on the first day of the tournament. The two ratings are not necessarily identical. Indeed, the reference rating does not necessarily take into account the results of tournaments played just before the World Open (recall that each World Open starts beginning of July). For instance, prior to 2008, when the June USCF reference rating was used, all results obtained by a player in June are not incorporated in the reference rating. Even after 2008, when the July USCF rating was applicable, results of matches played in June may not be taken into account because of time lags (the moment a given game is played and the moment the associated score is transmitted to U.S.C.F. officials and actually recorded). Both ratings are, however, observed in our data set (the reference rating through the World Open database, and the tournament rating through the U.S.C.F. online database).

Both ratings are interesting. The reference rating is the Elo rating known to players when they register for the World Open tournament (registration typically takes place a few weeks or months prior to the start of the tournament). So they are likely to use this rating in their decision whether or not to participate in the World Open. Organizers use the reference rating to decide whether or not to approve the choices of players. The tournament rating is an updated rating and as such it is a better measure of the player's strength at the beginning of the tournament. Both of them are, whenever necessary, normalized as described above.

Figure 1a shows how players are distributed according to their normalized reference rating. Here we have pooled all our data together (all four sections and all twelve tournament years). The ratings are grouped into bins of 20 Elo points: roughly $10 \%$ of players have a normalized reference rating between 0 and 19, $8 \%$ between 40 and 59, etc. The distribution has the form of a uniform distribution but this hides some disparities between the sections which will be detailed in Section 5.4. At the extremes of the figure there are the categories " $<0$ " and " $>199$ ". The ">199" category includes all individuals who played in a section under their "natural" section, i.e., the section to which their reference rating belonged. Fortunately there is only a handful of players in this category ( 5 are in U1600, 1 in U1800). This means that World Open officials carefully applied the rules and did not allow (bar the 6 exceptions) players to register in sections below their rating. The " $<0$ " category includes individuals who, on the contrary, played above their natural section. This was allowed under the World Open rules. Thus a player like Bob $\left(R_{B}=1970\right)$ could choose to play in his natural section (U2000), or be more ambitious and opt for one of the sections above (U2200, U2400, or even Open). As shown in Figure 1a, on average almost $11 \%$ of players are in the " $<0$ " category.

Figure $1 b$ displays the distribution of players according to their normalized tournament rating, again by pooling all sections and years. The figure is quite similar to the previous one except that there are much more observations concentrated in the ">199" category: on the first day of the World Open 466 players ( $5 \%$ of sample) had a normalized tournament rating above 200 , compared to only 6 players with a normalized reference rating above this threshold. These are participants who took part in (at least) one tournament between the date of reference rating and beginning of the tournament, and they won Elo points, resulting in their tournament rating being higher than the upper limit of the section wherein they participate. They are not the only players, however, for whom the reference and tournament ratings are different. Indeed, for any player who played matches just before the World Open the two ratings may potentially not be the same. For about $25 \%$ of players in our sample the reference rating decreased (relatively to the tournament rating), for $36.4 \%$ it remained constant, and for $38.6 \%$ it increased. On average, 


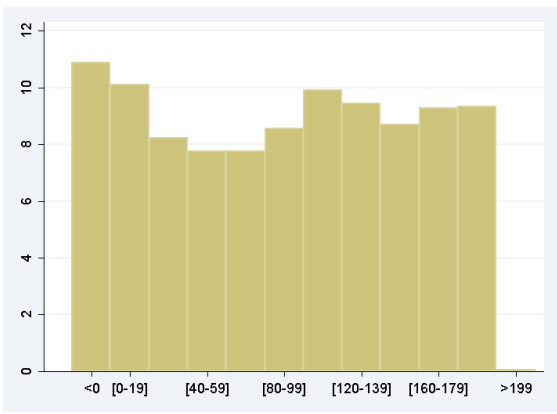

Figure 1a: Distribution of normalized reference rating (combined data from all sections and years)

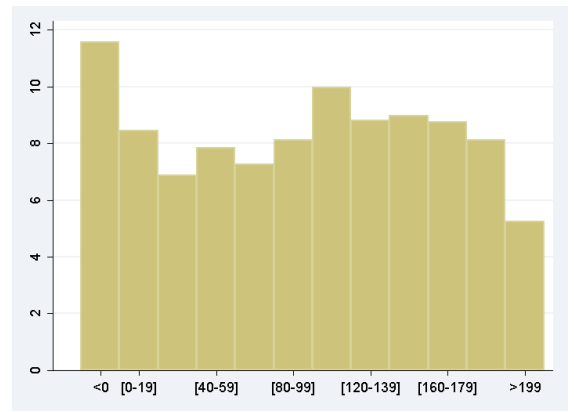

Figure 1b: Distribution of normalized tournament rating (combined data from all sections and years)

the normalized tournament rating exceeds the normalized reference rating by $2 \%$. Table A.8 in the Appendix tabulates the two ratings against each other for all possible Elo bins.

\section{Data set}

Our data set is constructed by combining information from two sources. First we use the World Open web site to collect data on chess participants in each tournament (first and last names, state or country of origin, sections wherein they played, all pairings and game results, reference ratings, prize amounts won by players). Second we use the USCF web site to extract monthly information on official Elo ratings of USCF-registered players and the tournaments wherein they played. This information allows us to define, for each year, the population of US chess players potentially able to participate in the World Open. It also allows us to determine the chess history of all these players prior to a given tournament. The two sources could be linked through the first and last names of players. ${ }^{13}$ As indicated in Table 1, a total of 9,632 players participated in the four sections of the World Open during the period 2001-2012.

From this initial sample we dropped foreign players (they typically do not have a USCF rating but only the Elo rating from their national federation), players who were labeled as "Fillers" in the World Open data basis (these players generally played just one match, and were sporadically added by World Open officials to a particular section and round to get even numbers of players), and persons who played no game at all in a World Open (they registered but did not play). These eliminations reduced the sample to 8,224 players (1,663 in U2200, 2,238 in $\mathrm{U} 2000,2,238$ in U1800, and 2,085 in U1600). ${ }^{14}$

\section{$5 \quad$ Descriptive Statistics}

\subsection{Players' characteristics}

Table 2 contains summary statistics on the geographic origin of players. The left panel is based on a sample where the tournaments of 2001, 2002, and 2006 are excluded (for these years information on state of origin is missing in the World Open records), and the right panel is

\footnotetext{
${ }^{13}$ In the World Open files many names are badly spelled. We could fortunately recover and match almost all players thanks to the fact that the USCF database indicates if a player played the World Open in a given year.

${ }^{14}$ Among the 8,224 players there are individuals who have participated in a World Open in different years. This panel aspect of the data is not exploited in this paper.
} 
based on the full sample (after replacing missing observations by states where players lived in 2012, as referenced in the USCF database). To simplify the table, states have been classified into six groups: Pennsylvania, Surrounding states (states around Pennsylvania), Center, Center East, Center West, East, and West. See the Appendix for the precise list of states within each group.

Table 2: Geographic Origin of Players

\begin{tabular}{rrrrr}
\hline \hline & \multicolumn{2}{c}{ Sample (I) } & \multicolumn{2}{c}{ Sample (II) } \\
& Freq. & Pct. & Freq & Pct. \\
\hline Center & 524 & 8.73 & 721 & 8.77 \\
Center East & 478 & 7.96 & 718 & 8.73 \\
Center West & 128 & 2.13 & 174 & 2.12 \\
East & 1,342 & 22.35 & 1,825 & 22.19 \\
Surrounding states & 2,354 & 39.20 & 3,162 & 38.45 \\
Pennsylvania & 839 & 13.97 & 1,120 & 13.62 \\
West & 340 & 5.66 & 504 & 6.13 \\
Total & 6,005 & 100.00 & 8,224 & 100.00 \\
\hline Footnotes: Sample (I): All years except 2001, 2002, and 2006. \\
Sample (II): All years. Geographic areas are defined in the Appendix.
\end{tabular}

Comparing the two panels, it turns out there is little difference. Apparently it is not problematic to define the geographic origin of players (in 2001, 2002, and 2006) as it is defined in 2012. Players come from all over the U.S. to play the World Open but slightly more than half of them originate from Pennsylvania and surrounding states. About $22 \%$ of players are from the East coast states and $9 \%$ from the Center. Relatively few of them are from the West or Center West states (together 8.25\%), which is not surprising given that these states are furthest away from the tournament location.

Table 3 displays summary statistics on several variables constructed from the past Elo ratings and chess activities recorded in the USCF online database. ${ }^{15}$ Monthly official Elo ratings are available between January 1991 to December 2012. The earliest month a player is observed corresponds to the moment this player registered as a USCF player. We define a player's chess-age, in a given year, as the difference between this year and the month of initial registration. Hence if a player registered after January 1991, chess-age is uncensored (87\% of observations). For players observed in all months between January 1991 and December 2012 (i.e., they became member prior to January 1991), chess-age is censored (13\%).

The main takeaway from Table 3 is that most players (despite being amateurs) have much experience and actively play chess before participating in a World Open. To begin with, $90 \%$ of them had a USCF rating for more than 2 years before participation, and $50 \%$ for more than 8 years. The rating trend, defined as the reference rating minus the average of Elo ratings during the 12 months prior to the World Open, is on average equal to almost 38 points. In the ten years preceding the World Open, participants have on average taken part in almost 65 chess tournaments or competitions. They are also quite active during the months just before the

\footnotetext{
${ }^{15}$ The USCF does not disclose any demographic or socio-economic information about its members. In particular we do not know their gender. Browsing the names, it is apparent, however, that a large majority of players is male. To verify this impression more formally, we used a database linking first names to gender provided by the US census (the database uses the 1990 census, see http://www.census.gov/genealogy/www/ data/1990surnames/names_files.html). A first name match was found for about $80 \%$ of the players. Among those, $95 \%$ have a male first name.
} 
Table 3: Chess History of World Open Players

\begin{tabular}{|c|c|c|c|c|c|c|c|c|c|c|}
\hline & $\mathrm{N}$ & mean & sd & $\min$ & p10 & p25 & p50 & p75 & p90 & $\max$ \\
\hline Chess age (years) & 8224 & 8.58 & 5.09 & 0.00 & 2.00 & 4.00 & 8.00 & 12.00 & 16.00 & 21.00 \\
\hline Rating trend & 8081 & 37.81 & 77.52 & -309.00 & -22.67 & -3.00 & 12.50 & 60.00 & 133.00 & 777.00 \\
\hline \# events in past 10 years & 8224 & 64.65 & 75.54 & 0.00 & 6.00 & 17.00 & 41.00 & 86.00 & 151.00 & 961.00 \\
\hline \# events in January-May & 8224 & 4.97 & 6.38 & 0.00 & 0.00 & 1.00 & 3.00 & 7.00 & 12.00 & 77.00 \\
\hline \# events in June & 8224 & 0.99 & 1.57 & 0.00 & 0.00 & 0.00 & 0.00 & 1.00 & 3.00 & 18.00 \\
\hline \# World Opens in past & 8224 & 2.87 & 3.35 & 0.00 & 0.00 & 0.00 & 2.00 & 4.00 & 8.00 & 20.00 \\
\hline Provisory rating & 8224 & 0.03 & 0.17 & 0.00 & 0.00 & 0.00 & 0.00 & 0.00 & 0.00 & 1.00 \\
\hline Active last 12 months & 8181 & 0.89 & 0.31 & 0.00 & 0.00 & 1.00 & 1.00 & 1.00 & 1.00 & 1.00 \\
\hline Active last $13-24$ months & 8181 & 0.85 & 0.35 & 0.00 & 0.00 & 1.00 & 1.00 & 1.00 & 1.00 & 1.00 \\
\hline Quick/regular chess ratio & 6335 & 0.93 & 0.09 & 0.33 & 0.82 & 0.89 & 0.94 & 0.98 & 1.02 & 1.33 \\
\hline
\end{tabular}

World Open: between January and May they played on average in 4.97 events, and during the single month of June in 0.99 events. Players are also familiar with World Open tournaments since on average they have participated in 2.87 of them. Almost $30 \%$ of participants, however, have never played in any World Open before. Only $3 \%$ of participants have a so-called provisory rating, meaning that $97 \%$ of them have played at least 25 games officially recognized by the USCF. Around $89 \%$ of players have been active in the 12 months preceding the World Open (they have played in at least one competition or tournament during the past year), and $85 \%$ in the period between 13 and 24 months prior to the tournament. Finally, the ratio of the quick rating (rating established for games with a short time limit) over the regular rating equals 0.93 on average, so the latter usually exceeded the former, but about $10 \%$ of players actually have a better quick rating.

\subsection{Prizes in the WO}

About six months before the start of each tournament, the World Open announces the number of prizes that can be won in each chess section and all corresponding "guaranteed" prize amounts. These amounts correspond to the minimal prizes awarded to prize winners in each section. As will be seen below, the actually awarded prizes always exceed the guaranteed prizes, but the differences are generally small. ${ }^{16}$ By summing over all guaranteed prizes in a given section we obtain the total guaranteed prize fund allocated to that section.

\subsubsection{First prize and total prize fund}

Table 4 shows, for each year and section, the guaranteed first prize (the minimal amount awarded to the winner of a section) and the realized first prize (amount actually awarded to the winner). The table also lists per section and year the guaranteed total prize fund (sum of all guaranteed prizes) and realized total prize funds. All monetary amounts correspond to current U.S. dollars.

The realized first prizes and total prize funds are either slightly above or equal to the guaranteed amounts. This implies that players could safely base their participation decision on the guaranteed amounts (announced before each tournament). Between 2001 and 2005 all guaranteed first prizes and actual first prizes are equal to $\$ 10,000$ for all four sections. Between

\footnotetext{
${ }^{16}$ For the years 2006-2012 (except 2009) the World Open web site also listed "projected" prize amounts. Projected prizes were based on an estimate of the total number of full-fee-paying participants in each of these years. In practice these projected prizes were substantially above the guaranteed and actual prizes.
} 
Table 4: First prize and total prize fund $(\mathrm{k} \$)$ per year and section

\begin{tabular}{ccccccccccccccc}
\hline \hline & & 2001 & 2002 & 2003 & 2004 & 2005 & 2006 & 2007 & 2008 & 2009 & 2010 & 2011 & 2012 \\
\hline \multirow{2}{*}{ U1600 } & Guaranteed 1st prize & 10.0 & 10.0 & 10.0 & 10.0 & 10.0 & 15.0 & 14.0 & 16.0 & 12.0 & 8.4 & 11.25 & 8.8 \\
& Realized 1st prize & 10.0 & 10.0 & 10.0 & 10.0 & 10.0 & 17.7 & 14.6 & 16.0 & 12.0 & 10.3 & 11.5 & 9.3 \\
& Guaranteed total fund & 24.9 & 24.9 & 24.9 & 24.8 & 24.8 & 41.6 & 36.0 & 41.1 & 27.5 & 19.3 & 29.3 & 23.3 \\
& Realized total fund & 24.9 & 24.9 & 24.9 & 24.8 & 24.8 & 49.7 & 38.4 & 41.1 & 30.5 & 26.2 & 30.1 & 24.5 \\
U1800, U2000, & Guaranteed 1st prize & 10.0 & 10.0 & 10.0 & 10.0 & 10.0 & 15.0 & 14.0 & 16.0 & 14.0 & 9.1 & 13.5 & 10.4 \\
and U2200 & Realized 1st prize & 10.0 & 10.0 & 10.0 & 10.0 & 10.0 & 17.7 & 14.6 & 16.0 & 14.0 & 11.5 & 14.0 & 11.0 \\
& Guaranteed total fund & 24.9 & 24.9 & 24.9 & 24.8 & 24.8 & 41.6 & 36.0 & 41.1 & 30.5 & 20.7 & 32.0 & 25.7 \\
& Realized total fund & 24.9 & 24.9 & 24.9 & 24.8 & 24.8 & 49.7 & 38.4 & 41.1 & 33.5 & 27.2 & 32.8 & 27.0 \\
\hline
\end{tabular}

2006 and 2012, the former are generally slightly below the latter. During this period the prizes in U1800, U2000, and U2200 are identical, and in most years a bit higher than those in U1600: winners of U1600 collected between $\$ 9,300$ (2012) and $\$ 17,700$ (2006), whereas in the other three sections they earned between $\$ 11,000$ (2012) and $\$ 17,700$ (2006). All awarded first prizes listed in the table correspond to attributed amounts in the absence of ties. In case multiple players tied for first place, the awards had to be shared. More precisely, if $n$ players tied first, they had to equally share the sum of the first until the $n$-th prize. ${ }^{17}$ Analogous sharing rules were applied if multiple players tied for second place, or third place, etc. Note that the amounts given to World Open winners are substantial. As a point of comparison, the annual median household income in the United States in 2001 was $\$ 42,228$ and in $2006 \$ 48,200{ }^{18}$ First prizes are also high compared to what amateurs can win in other chess tournaments. In the 2012 London Chess Classic event, for instance, the winner of U2200 was guaranteed only $£ 250$ (approximately $\$ 400$ ). Similarly, in the 2012 Paris Chess Tournament, the winner of the OPEN A (a section for players ranked between 1,800 and 2,300) could expect to collect $€ 1,500$ (around $\$ 2,000$ ).

Guaranteed and actual total prize funds fluctuate between 20,000 and 30,000 for most tournaments. Between 2006 and 2008, however, they are significantly higher and vary between $\$ 40,000$ and $\$ 50,000$. Section 7 investigates how this increase in the prize budget affects players' participation decisions. The awarded total prize funds are on the organizer's cost side while the registration fees paid by participants are on the benefit side. These fees equal $\$ 247$ per player between 2001 and 2005, $\$ 367$ between 2006 and 2008, and $\$ 317$ after 2009. Multiplying, for each tournament, the registration fee by the number of participants (taking into account that grand masters do not pay a fee), and subtracting the total amount of actually distributed prizes, indicates that the World Open organizers ran a surplus in all years (between $\$ 90,000$ in 2005 and $\$ 181,000$ in 2012). This back-of-the-envelope approach, however, does not take into account the costs of renting the tournament venue nor the remunerations earned by tournament directors.

\subsubsection{Structure of Prizes}

Figure 2 shows the structure of ex-ante announced guaranteed prizes (averaged over all years and sections). The first prize is normalized to 100, and all other prizes are expressed as percentages of the first one. The World Open prize structure is reminiscent of the structure adopted in many other sports tournaments: winners get by far the largest share of the cake

\footnotetext{
${ }^{17}$ Suppose, for example, that the first-prize equals $\$ 10,000$, the second-prize $\$ 5,000$, and the third-prize $\$ 3,000$, and that three players finished first (i.e., they ended up with the same number of points), then each would receive $\$ 18,000 / 3=\$ 6,000$.

${ }^{18}$ Source: US Census Bureau, http://www.census.gov/prod/2002pubs/p60-218.pdf.
} 
and the successive prizes received by the lower-ranked players rapidly decline. On average, the second prize is half the first prize, the third prize half the second, and the fourth half the third. The gap between the fourth and fifth is usually less (between 25 and $30 \%$ ), and, beyond the 10th rank, prizes remain quite similar.

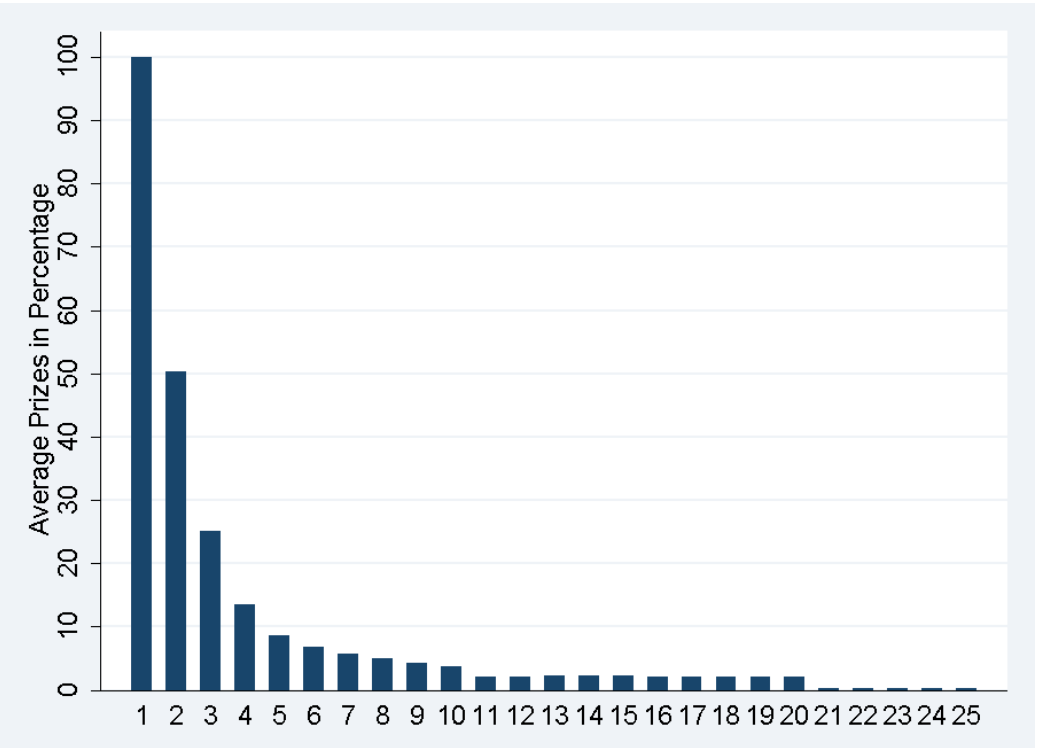

Figure 2: Prizes as percentage of the first prize (average over all years and sections)

Table A.1 in the Appendix shows the number of awarded prizes per year and section. It shows that for each year the number of prizes varied substantially across the four sections. For example, in 2006, the number of prizes given in U1600 was 42, and only 26 in U2000. These differences are due to variations in the number of ties across sections (there is hardly any variation in the number of ex-ante announced number of prizes across sections in a given year). Between 2001 and 2008 the average number of awarded prizes (averages calculated over the four sections) varied between 22.3 (in 2002) and 34.2 (2006). Since 2009 it has dropped and varied between 17.6 (2011) and 19.8 (2012).

\subsection{Player performance}

\subsubsection{Probability to win a prize and net gain}

Figure 3 shows how the normalized tournament rating is distributed among prize-winners. Combining all tournament years and sections, it turns out that 1,142 players have won a prize (regardless of whether it is a first prize, second prize, etc.). ${ }^{19}$ About $30 \%$ of these winners have a normalized tournament rating above 180 (last two bars in the histogram) and almost $70 \%$ have a rating above 140 (last four bars). So, as expected, most winners are players who have either a tournament rating near the upper bound of the section wherein they play (normalized tournament rating between 140 and 200) or a rating above the upper bound of their section (normalized tournament rating above 200, i.e., players in the " $>199$ " bin). To confirm this finding, we ran a logit regression of a variable indicating whether a player has won a prize on the normalized tournament ratings and a set of control variables (variables indicating the geographic origin of players and their chess history, i.e., the variables listed in Tables 2 and 3). The results are in Table A.2 in the Appendix. The estimations indicate that players with a

\footnotetext{
${ }^{19}$ Conclusions are similar when we focus only on players who have won the first prize.
} 
normalized tournament rating below 80 have a lower probability of winning a prize while those rated above 120 have a higher probability.

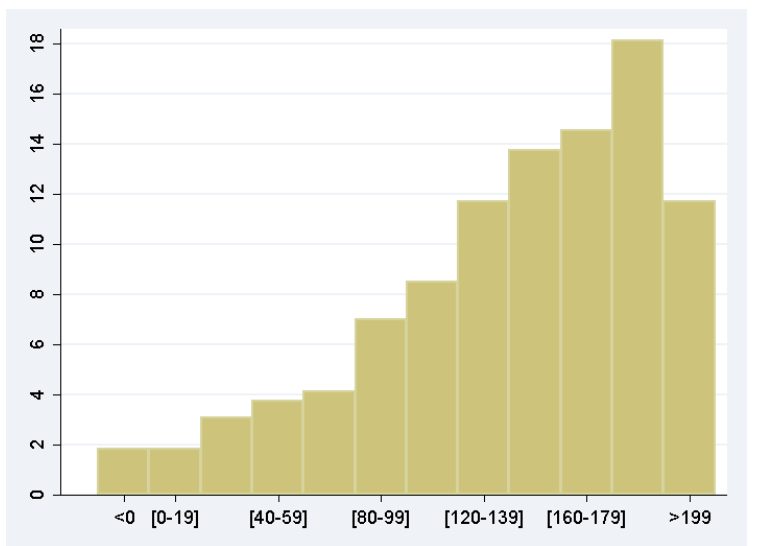

Figure 3: Normalized tournament rating of winners of a prize (combined data from all sections and years)

To study the monetary benefit of participating in a World Open, we regress a player's net gain (defined as prize amount minus entry fee in $\$$ of 2012) on normalized tournament ratings and our control variables. Estimations are based on data from all years and sections pooled together, and can be found in Table A.3 in the Appendix. Column "All" reports results based on all players. For players with a normalized tournament rating below 140 the net gains are negative and significantly different from zero (depending on the range of Elo ratings, net losses vary between roughly between $-\$ 300$ and $-\$ 200$ ). For players ranked between 140 and 200 the net gain is not significantly different from zero, i.e., they break even. Players with a normalized rating above 200 have significant and positive expected gains: on average their net benefit is around $\$ 130$. The estimations shown in the column headed "Above P95" are based only on players who are in the top $5 \%$ of prize earners within their section and rating bin. For example, among players rated between 60 and 80 and with earnings above the 95th percentile in their section, the average net gain is around $\$ 1,470$. The results show that the highly rated topearners gained substantial amounts. Those between 160 and 180, for instance, have an average net gain around $\$ 5,000$, while those above 200 around $\$ 6,000$.

\subsubsection{End-of-tournament scores}

Table A.4 in the Appendix reports results of OLS regressions of the final score on the normalized tournament rating and its square, and our control variables. For these regressions only players who played 9 games out of 9 are included (that is players who dropped out of the tournament before the end are excluded). We report estimates based on both the full data set (all sections and years pooled together) and the four sections separately. In each case both the rating and its square are significant (except U1600 where only the rating is significant), and the relationship between score and rating turns out to be positive and convex. The marginal score therefore increases with the normalized rating.

\subsubsection{Rating gains}

The statistics on player performance shown so far indicate that highly rated chess players earn relatively more money and score better. At first sight one may also expect them to gain more Elo points during the tournament. We check this by regressing the difference $\mathrm{R}^{\text {after }}-\mathrm{R}^{\text {before }}$ 
on the normalized tournament rating indicators. Here $\mathrm{R}^{\text {before }}$ is the Elo rating at the beginning of the tournament (tournament rating), $\mathrm{R}^{\text {after }}$ at the end, and the difference is defined by (2). The regression results are reported in Table A.5. Column (I) reports the results based on all 9,044 players for a specification without control variables. Players with a negative normalized Elo rating gain on average almost 15 points more than those rated between 100 and 120 (the reference category; the estimate of the constant shows that players in this category gain around 4 points), and this effect is significantly different from zero. On the other hand, players with a normalized rating above 200 lose 10.148 rating points when compared to the reference group. Players rated between 120 and 200 lose points while those rated between 0 and 100 gain, although the coefficients are not statistically significant for all bins. Column (II) lists estimates for a specification that adds geographic controls and chess history controls. The results are now even stronger and more pronounced. The results given in column (III) are based on the sample of players who have played all 9 games. The sample size is thereby reduced from 9,044 to 5,933. Qualitatively the results are in line with those of (II) although the number of significant variables is now slightly lower. Table A.5 thus suggests that players with high normalized ratings gain not more but less Elo points than lowly rated players. This counterintuitive result is in fact compatible with the idea that chess players self-select into the World Open on the basis of their observed Elo rating and unobserved strength-shock. As detailed in Section 6, participants situated near the lower bound of their chess section have, on average, a relatively high strengthshock (compared to participants whose rating is near the upper bound), explaining why they manage to perform better than expected (given their observed strength).

\subsection{Tournament participation}

Figures 4a-7b show, for each of our four chess sections, the histogram of the reference rating among World Open participants (left-hand side panel) and the histogram among all USCF players (right-hand side panel). In constructing these figures we pooled all twelve tournament-years together, ${ }^{20}$ and excluded participants who played above their natural sections. For example, participants with a reference rating between 1,600 and 1,799 (the natural section for such players is therefore U1800), who chose to play in say U2000, are not counted in the histogram plot 5a. Note that by comparing the left-hand panels with the corresponding right-hand panels we informally test for the presence of selective entry into World Open tournaments.

For each section the histogram of reference ratings among World Open participants looks quite different from the one among USCF members. The histograms for the latter tend to decrease with reference ratings. This reflects the fact that for the segment of USCF players we are studying (those with a reference rating between 1,400 and 2,200), the empirical distribution function of ratings decreases. ${ }^{21}$ The histograms for World Open participants are, on the contrary, either increasing (Figures 4a and 5a) or flat functions (Figures 6a and 7a) of ratings. The general message that emerges from the complete set of figures is that lowly-rated World Open participants are under-represented (relatively to the USCF population), and highly-rated participants over-represented.

\footnotetext{
${ }^{20}$ Conclusions remain similar when graphs are plotted separately for each year.

${ }^{21}$ Calculated over all USCF members, the distribution function has a unique maximum around 800, and monotonously decreases beyond this point.
} 


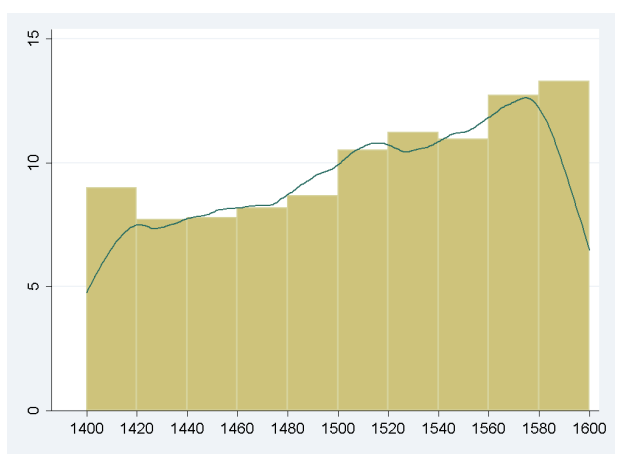

Figure 4a: U1600 section (1,400-1,599)

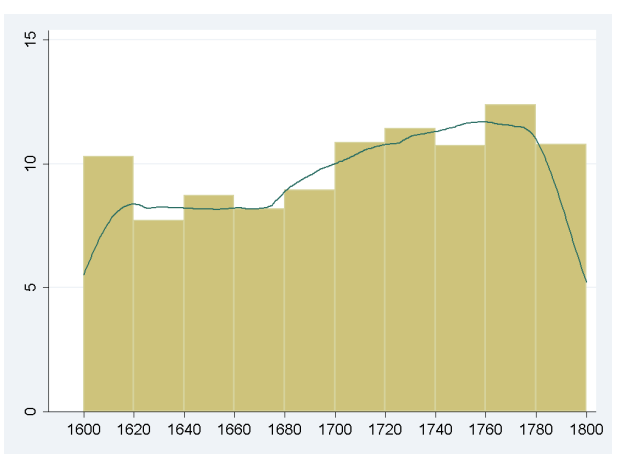

Figure 5a: U1800 section (1,600-1,799)

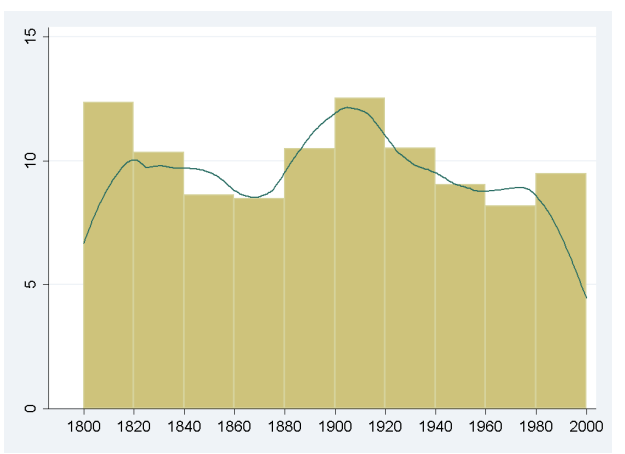

Figure 6a: U2000 section (1,800-1,999)

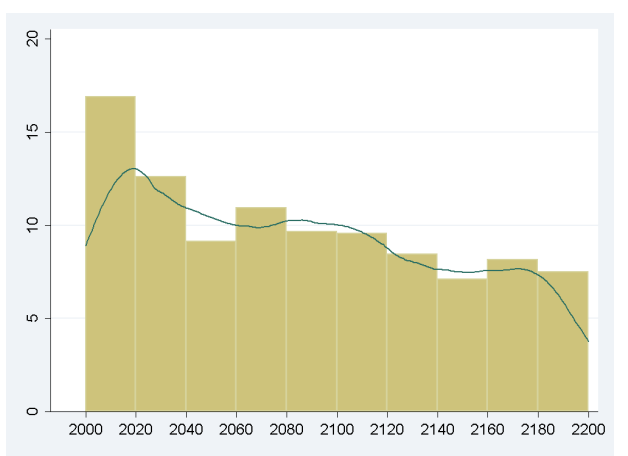

Figure 7a: U2200 section $(2,000-2,199)$

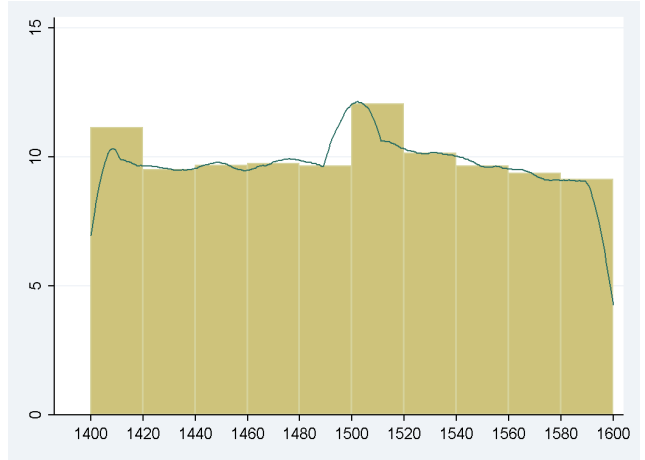

Figure 4b: USCF players $(1,400-1,599)$

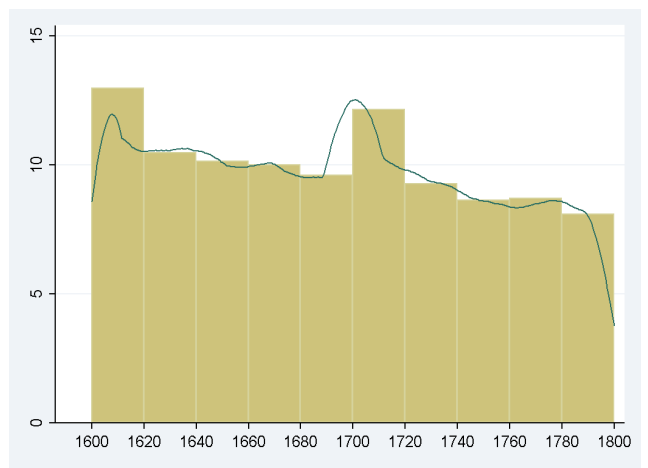

Figure 5b: USCF players $(1,600-1,799)$

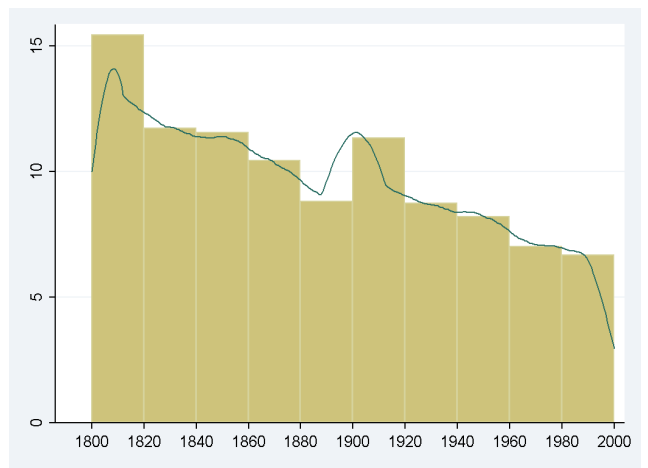

Figure 6b: USCF players $(1,800-1,999)$

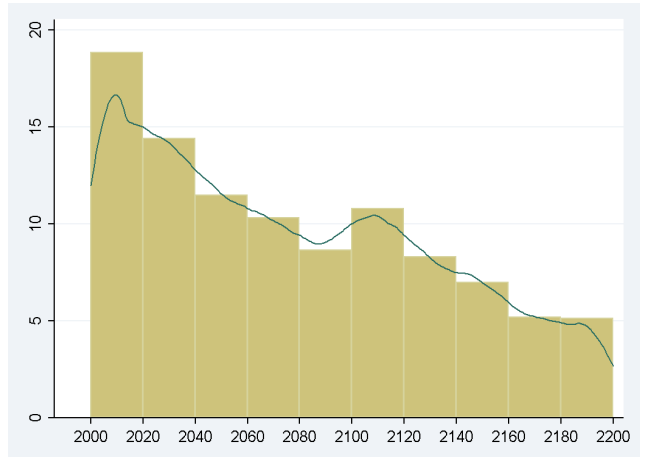

Figure 7b: USCF players $(2,000-2,199)$ 


\section{Selection Model}

This section proposes a simple model explaining how chess players decide to participate or not in a World Open tournament. Our model focusses on the choice between participating in one's natural section, or not participating at all. That is we abstract from the possibility that players may decide to compete in a section above the section to which their current rating belongs. We have seen in Section 3.2, however, that this concerns only a small fraction of World Open participants.

It is assumed that players participate if their expected profits exceed participation costs. The expected profit equals the expected prize amount that can be won plus a privately observed benefit to play in a tournament. The expected prize amount depends on the player's normalized rating and a temporary player-specific strength-shock. This shock is also private information and reflects the fact that current form and strength may deviate from the normalized rating. Finally, the cost of participation is the sum of a common cost parameter and a player-specific cost component.

In this setting we show that players auto-select into the tournament on the basis of their observed normalized ratings, and their unobserved parameters (private benefits, strength-shocks, and costs). This auto-selection leads to predictions on the link between participation decisions on the one hand and ratings and prize levels on the other. It also leads to a prediction on the link between the expected value of the strength-shock among participating players and their rating, which in turn implies certain testable restrictions on the relationship between the expected game outcome and the players' ratings. These predictions are confronted with the data in Section 7.

When deciding to participate in a World Open, players' actual strengths may deviate from their normalized ratings. ${ }^{22}$ Let $\varepsilon_{i}$ be the strength-shock of player $i\left(\varepsilon_{i}\right.$ can be positive or negative) and, as above, $r_{i}$ the normalized rating of this player, then $r_{i}+\varepsilon_{i}$ represents $i$ 's actual chess strength level just before and during the tournament. Let $G\left(r_{i}+\varepsilon_{i}\right)$ denote the expected prize amount of player $i, b_{i}$ the private benefit to play in the tournament (after all chess players enjoy playing chess independently of any pecuniary considerations), $c$ the average cost of participation common to all players (which can be interpreted as the registration fee plus average travel and hotel expenses), and $c_{i}$ the idiosyncratic departure from this average cost (hence $c_{i}$ can be positive or negative). Then, the utility of player $i$ taking part in the tournament is

$$
G\left(r_{i}+\varepsilon_{i}\right)+b_{i}-c_{i}-c=G\left(r_{i}+\varepsilon_{i}\right)+u_{i}-c,
$$

where $u_{i}=b_{i}-c_{i}$ is the net private benefit to play.

Players are thus characterized by the triplet $(\varepsilon, u, r)$, where $r$ is commonly known and $\varepsilon$ and $u$ are privately observed. These variables are treated as random variables. We assume that, in the population of chess players, both $\varepsilon$ and $u$ are independent from $r$ (ratings are unrelated to player-specific costs and benefits, and temporary deviations in chess strength). The two shocks are, however, allowed to be dependent variables. ${ }^{23}$ Let $\phi(\varepsilon \mid u)$ be the density function of $\varepsilon$ given $u$ defined on $[\underline{\varepsilon}, \bar{\varepsilon}]$, and $\Phi(\varepsilon \mid u)$ the corresponding conditional distribution function. Finally, let $\psi(u)$ denote the density of $u$ on an interval $[\underline{u}, \bar{u}]$, and $\Psi(u)$ the corresponding density function.

\footnotetext{
${ }^{22}$ Their actual playing level may, for instance, be higher than the official rating if they have trained intensively just before the tournament, or lower if they have recently suffered from a lot of stress at work.

${ }^{23}$ Dependence between the shocks may arise for example if a player has a bad flu. The pleasure to play and the physical costs of travelling would then be high $(u<0)$, but at the same time the ability to play chess well would be reduced $(\varepsilon<0)$. As another example, imagine a player who has to be in Philadelphia for professional reasons. Travel costs would in that case be low (high $u$ ), but exhaustion from work would result in a low value of $\varepsilon$.
} 
Given the complexity of the World Open tournament it seems not feasible to find the equilibrium expected prize amount function. ${ }^{24}$ Fortunately it is possible to obtain our predictions without knowing explicitly $G($.$) . We only need to make one assumption on this function,$ namely that it is strictly increasing. This is a weak and natural assumption. It implies that $G($.$) is differentiable almost everywhere and that its derivative, denoted g($.$) , is positive.$

In equilibrium, player $i$ participates if and only if:

$$
G\left(r_{i}+\varepsilon_{i}\right)+u_{i} \geq c .
$$

Let $\widetilde{\varepsilon}(u, r)$ (resp. $\widetilde{u}(\varepsilon, r))$ denote the unique solution to the equation $G(r+\varepsilon)+u=c$. Formally,

$$
\widetilde{\varepsilon}(u, r)= \begin{cases}\underline{\varepsilon} & \text { if } c<u \\ G^{-1}(c-u)-r & \text { if } c-P_{1} \leq u \leq c \\ \bar{\varepsilon} & \text { if } u<c-P_{1}\end{cases}
$$

(resp. $\widetilde{u}(\varepsilon, r)=c-G(r+\varepsilon))$. All players with $\varepsilon \geq \widetilde{\varepsilon}($ resp. $u \geq \widetilde{u})$ participate. The threshold value $\widetilde{\varepsilon}(u, r)$ can take three forms depending on the value of $u$. If $u$ is larger than $c$ then (as $G \geq 0$ ) the participation constraint (3) is non-binding: all players with such a value of the private benefit participate whatever their value of $\varepsilon$, and hence $\widetilde{\varepsilon}(u, r)=\underline{\varepsilon}$. On the contrary, if $u$ is lower than $c-P_{1}$ (where $P_{1}$ is the first prize, i.e., the maximum amount which can be won), then no one participates regardless of $\varepsilon$, and hence $\widetilde{\varepsilon}(u, r)=\bar{\varepsilon}$. When $u$ is between these values we have $\widetilde{\varepsilon}(u, r)=G^{-1}(c-u)-r$.

Proposition 1 states how the participation decision varies with the rating and with the level of prizes awarded at the tournament.

Proposition 1 (Participation). $i$. We have $\partial \widetilde{\varepsilon} / \partial r<0$ (for all values of $u$ such that $c-P_{1} \leq u \leq$ c), and $\partial \widetilde{u} / \partial r<0$. More players therefore participate as $r$ augments. ii. Let $G(x)=\lambda H(x)$ with $\lambda>0$. We have $\partial \widetilde{u} / \partial \lambda=-H(r+\varepsilon)$ and $\partial^{2} \widetilde{u} / \partial \lambda \partial r<0$. Therefore, more players participate when $\lambda$ augments, and this effect is relatively larger for higher values of $r$.

Proof. i. For values of $u$ such that $\widetilde{\varepsilon}$ is an interior solution we have $\partial \widetilde{\varepsilon} / \partial r=-1$. Furthermore, $\partial \widetilde{u} / \partial r=-g(r+\widetilde{\varepsilon})<0$ since $G$ is assumed to be strictly increasing. ii. We have $\partial^{2} \widetilde{u} / \partial \lambda \partial r=$ $-h(r+\varepsilon)<0$ because $H$ is strictly increasing (since $G$ is assumed to be strictly increasing).

According to the first part of the proposition, the participation rate in the World Open should increase with the normalized rating $r$ : participants with low normalized ratings are under-represented relatively to the total population of chess players, and those with high ratings are over-represented. The second part states that, if all prizes in a tournament are augmented by the same factor (and under the simplifying assumption that this change in prizes does not affect the equilibrium winning probabilities discussed in footnote 24), the number of participants augments and this increase is larger the higher $r$.

Next we investigate how the expected strength-shock among participants, denoted $\widehat{\varepsilon}(r)$, varies with the normalized rating. If this expectation fluctuates with $r$ the expected true strength of players is no longer adequately measured by their observed ratings alone. Instead, the true chess strength of participants with rating $r$ is on average equal to $r+\widehat{\varepsilon}(r)$. To study $\widehat{\varepsilon}(r)$ it is convenient to first introduce $\widehat{\varepsilon}(u, r)$, the expected strength-shock $\varepsilon$ among participants with

\footnotetext{
${ }^{24}$ The function $G($.$) is of the form \sum \pi_{k} P_{k}$ where $\pi_{k}$ is the probability that a player ends the tournament at rank $k$ and $P_{k}$ the prize the player will then receive. The equilibrium probabilities are difficult to derive because they depend on the equilibrium distribution of the types of the players who participate. Solving the model is also complicated because of the tying rules (players share prizes if their end-of-tournament rankings are identical) and the fact that the tournament is made up of multiple rounds.
} 
rating $r$ and given $u$. Letting $p$ denote the participation indicator $(p=1$ if a player participates and zero otherwise), we have

$$
\widehat{\varepsilon}(u, r)=\mathbb{E}[\varepsilon \mid p=1, u]=\mathbb{E}[\varepsilon \mid \varepsilon>\widetilde{\varepsilon}, u]=\int_{\widetilde{\varepsilon}}^{\bar{\varepsilon}} \frac{\varepsilon \phi(\varepsilon \mid u)}{1-\Phi(\widetilde{\varepsilon} \mid u)} d \varepsilon .
$$

Lemma 1 states that this expected value of the strength-shock decreases with $r$ for values of $u$ such that $\widetilde{\varepsilon}$ is an interior solution.

Lemma 1. $\widehat{\varepsilon}(u, r)$ decreases with $r$ when $u$ is such that $c-P_{1} \leq u \leq c$ (otherwise $\widehat{\varepsilon}(u, r)$ is a constant function of $r$ ).

Proof. When $c-P_{1} \leq u \leq c$, the partial derivative of $\widehat{\varepsilon}(u, r)$ with respect to $r$ is:

$$
\frac{\partial \widehat{\varepsilon}(u, r)}{\partial r}=\frac{\partial \widetilde{\varepsilon}(u, r)}{\partial r}\left(\frac{\phi(\widetilde{\varepsilon} \mid u)}{1-\Phi(\widetilde{\varepsilon} \mid u)}\right)[\widehat{\varepsilon}(u, r)-\widetilde{\varepsilon}]=-\left(\frac{\phi(\widetilde{\varepsilon} \mid u)}{1-\Phi(\widetilde{\varepsilon} \mid u)}\right)[\widehat{\varepsilon}(u, r)-\widetilde{\varepsilon}]<0 .
$$

When $u>c$ (resp. $\left.u<c-P_{1}\right), \widehat{\varepsilon}(u, r)=\underline{\varepsilon}($ resp. $\widehat{\varepsilon}(u, r)=\bar{\varepsilon})$, and the derivative with respect to $r$ equals 0 .

The intuition behind this result is that when $r$ increases more players participate but these new players are the ones for whom it was not profitable to participate before because they had too low a $\varepsilon$. Therefore their inclusion into the tournament reduces the average value of $\varepsilon$.

The formal definition of $\widehat{\varepsilon}(r)$ is

$$
\begin{aligned}
\widehat{\varepsilon}(r) & =\mathbb{E}[\widehat{\varepsilon}(u, r) \mid p=1]=\int_{\underline{u}}^{\bar{u}} \frac{1-\Phi(\widetilde{\varepsilon} \mid u)}{\int_{\underline{u}}^{\bar{u}}(1-\Phi(\widetilde{\varepsilon} \mid u)) \psi(u) d u} \widehat{\varepsilon}(u, r) \psi(u) d u \\
& =\int_{\underline{u}}^{\bar{u}} \widehat{\varepsilon}(u, r) \omega(u, r) \psi(u) d u
\end{aligned}
$$

where

$$
\omega(u, r)=\frac{1-\Phi(\widetilde{\varepsilon} \mid u)}{\int_{\underline{u}}^{\bar{u}}(1-\Phi(\widetilde{\varepsilon} \mid u)) \psi(u) d u},
$$

and the expectation is with respect to $u$ given $p=1$. Since $\widehat{\varepsilon}(u, r)$ is decreasing with $r$ (or a constant function of $r$ when $u>c$ or $\left.u<c-P_{1}\right)$, the intuition is that $\widehat{\varepsilon}(r)$ should also decrease with $r$. Letting $h(\varepsilon \mid u)=\phi(\varepsilon \mid u) /(1-\Phi(\varepsilon \mid u))$ be the hazard rate of the distribution of $\varepsilon$ conditional on $u$, Proposition 2 shows, however, that this is not necessarily the case.

Proposition 2 (Selection). The derivative of $\widehat{\varepsilon}(r)$ with respect to $r$ is:

$$
\begin{aligned}
\frac{d \widehat{\varepsilon}(r)}{d r} & =\mathbb{E}\left[\frac{\partial \widehat{\varepsilon}(u, r)}{\partial r} \mid p=1\right]+\operatorname{Cov}[h(\widetilde{\varepsilon} \mid u), \widehat{\varepsilon}(u, r) \mid p=1] \\
& =-\mathbb{E}[h(\widetilde{\varepsilon} \mid u) \mid p=1] \mathbb{E}[\widehat{\varepsilon}(u, r)-\widetilde{\varepsilon}(u, r) \mid p=1]+\operatorname{Cov}[h(\widetilde{\varepsilon} \mid u), \widetilde{\varepsilon}(u, r) \mid p=1]
\end{aligned}
$$

where the expectations and covariances are with respect to $u$ given $p=1$. Each of the following conditions is sufficient for $\frac{d \widehat{\varepsilon}(r)}{d r} \leq 0$ :

$i$. The variables $\varepsilon$ and $u$ are independent and $h(\varepsilon \mid u) \searrow$ with $\varepsilon$.

ii. The variable $\varepsilon$ first-order stochastically decreases with $u$ (i.e. $h(\varepsilon \mid u) \nearrow$ with u) and $h(\varepsilon \mid u) \searrow$ with $\varepsilon$.

iii. The variable $\varepsilon$ first-order stochastically decreases with $u($ i.e. $h(\varepsilon \mid u) \nearrow$ with $u)$ and $h(\varepsilon \mid u)$ is constant with $\varepsilon$. 
iv. The variable $\varepsilon$ first-order stochastically decreases with $u$ (i.e. $h(\varepsilon \mid u) \nearrow$ with u) and $h \nearrow$ with $\varepsilon$, and $\frac{\partial h(\widetilde{\varepsilon} \mid u) / \partial u}{\partial h(\widetilde{\varepsilon} \mid u) / \partial \varepsilon} \geq \frac{1}{g(r+\widetilde{\varepsilon})}>0$ (where $\partial h(\widetilde{\varepsilon} \mid u) / \partial u$ is shorthand for the partial derivative of $h(\varepsilon \mid u)$ with respect to $u$ evaluated at $\varepsilon=\widetilde{\varepsilon}$, etc.).

$v$. The variable $\varepsilon$ first-order stochastically increases with $u$ (i.e. $h(\varepsilon \mid u) \searrow$ with $u$ ) and $h(\varepsilon \mid u) \searrow$ with $\varepsilon$, and $0<\frac{\partial h(\widetilde{\varepsilon} \mid u) / \partial u}{\partial h(\widetilde{\varepsilon} \mid u) / \partial \varepsilon} \leq \frac{1}{g(r+\widetilde{\varepsilon})}$.

Proof. See the Appendix.

In both equation 4 and 5 , the first term is always negative while the second (covariance) term can be positive or negative. Because of Lemma 1, the first term in 4 is indeed negative. The first term in 5 is also negative because a hazard function is by definition positive, and, by construction, $\widehat{\varepsilon}(u, r)>\widetilde{\varepsilon}(u, r)$. Proposition 2 gives the conditions under which the covariance term appearing in 5 is negative. These are necessary conditions for $d \widehat{\varepsilon}(r) / d r$ to be decreasing in $r$.

In the adverse-selection literature, it is often assumed that $h(\varepsilon \mid u)$ is increasing with $\varepsilon .{ }^{25}$ As item iv of Proposition 2 indicates, such an assumption on the hazard rate (together with the assumption that $\varepsilon$ first-order stochastically decreases with $u$ and the technical condition $\partial h(\widetilde{\varepsilon} \mid u) / \partial u / \partial h(\widetilde{\varepsilon} \mid u) / \partial \varepsilon \geq 1 / g(r+\widetilde{\varepsilon})>0)$ ensures that $d \widehat{\varepsilon}(r) / d r<0$. If the hazard is instead decreasing, we still have $d \widehat{\varepsilon}(r) / d r<0$ under the conditions listed in items i, ii, or v. Finally, as item iii indicates, if the hazard is constant (this corresponds to the case where $\varepsilon$ given $u$ is exponentially distributed) $\widehat{\varepsilon}(r)$ is decreasing in $r$ if $h(\varepsilon \mid u)$ increases with $u$.

\section{$7 \quad$ Empirical tests}

\subsection{Participation in World Open tournaments}

We first test the predictions listed in Proposition 1, that is we check whether highly-rated (resp. lowly-rated) participants are over-represented (resp. under-represented) relatively to the population of USCF members, and whether participation in World Open tournaments increases with the height of the prize fund. To do this we estimate the following logit model

$$
\operatorname{Pr}\left(p_{i t}=1 \mid x_{i t}\right)=\frac{\exp \left(x_{i t} \beta\right)}{1+\exp \left(x_{i t} \beta\right)}
$$

where $p_{i t}=1$ if USCF member $i$ decides to participate in the tournament held in year $t$, and $p_{i t}=0$ otherwise, $x_{i t}$ is a vector of explanatory variables, $\beta$ a vector of unknown parameters to be estimated, and

$$
\begin{aligned}
x_{i t} \beta= & z_{i t} \theta+\sum_{\substack{j=1 \\
j \neq 5}}^{10} \delta_{j} \times 1\left\{r_{i t} \in[20(j-1), 20 j)\right\} \\
& +\sum_{j=1}^{10} \alpha_{j} \times 1\left\{r_{i t} \in[20(j-1), 20 j)\right\} \times 1\{t \in\{2006,2007,2008\}\}
\end{aligned}
$$

where $z_{i t}$ is a vector containing a constant and control variables (region where player lives, past chess experience, dummy variables indicating in which section players play, etc.) and $\theta$ the associated parameter vector, $1\{A\}$ the indicator function equal to 1 if $\mathrm{A}$ is true and 0 otherwise,

\footnotetext{
${ }^{25} \mathrm{~A}$ necessary condition for $h$ to be increasing is either i) $\phi$ is a log-concave function, or ii) $\phi$ is increasing (see Bagnoli and Bergstrom (2005))
} 
and $r$ the normalized reference rating. Since $z$ includes a constant and each rating necessarily lies within one of the 10 bins (we focus on players who have chosen to play in their natural section, hence their normalized reference ratings are between 0 and 200), we should omit one of them as the reference category. For convenience we took the fifth bin, the interval $[80,100)$, as the reference category. If item i of Proposition 1 indeed holds we expect the estimates of $\delta_{j}$ to be negative for $j<5$ (under-representation of lowly-rated participants), and positive for $j>5$ (over-representation of highly-rated participants). If item ii also holds, we expect all $\alpha_{j}$ to be positive, with higher coefficients for larger values of $j$ (increased participation due to larger prize funds between 2006 and 2008, and the increase is amplified among top-rated players).

Table 5 reports the maximum likelihood estimates and asymptotic standard errors for different specifications of the logit model. Column I lists the results for the baseline specification in which $x$ only includes the rating interval indicators (i.e., $z$ and the interactions between year indicators and rating-interval indicators are excluded). In columns II-V we give the results for richer specifications where control variables and/or the interaction terms are added to the model. The different sets of results and the conclusions that can be drawn from them are strikingly similar across the different specifications. In all cases the estimates of $\delta_{1}, \delta_{2}, \delta_{3}$, and $\delta_{4}$ have negative signs, and they are statistically different from zero. The null hypothesis that $\delta_{6}$ equals zero is never rejected. Estimates of $\delta_{7}, \delta_{8}, \delta_{9}$, and $\delta_{10}$ are positive for all specifications, and the last three are significantly different from zero. We can reject the null that $\delta_{7}$ equals zero at the 5 or $10 \%$ level (we fail to reject it at conventional levels only once, for the specification of column IV). Overall these results are clearly in line with item i of Proposition 1. Regarding the $\alpha$ 's, most estimates are positive and have a tendency to increase with $j$ as predicted by item ii. However, we can reject the null hypothesis only for $\alpha_{7}, \alpha_{9}$, and $\alpha_{10}$. The results are in line with the second prediction but only for the most highly rated players.

Let us finally look at the effects of the control variables. Table 5 shows that chess players whose natural section is either U2200, U2000, or U1800 are more likely to participate in World Open tournaments than those belonging to U1600 (the reference category). A monetary incentive story cannot rationalize this finding since prize levels are comparable across the four sections. Apparently, more highly ranked chess players are intrinsically more motivated to participate, independently of financial considerations. USCF members originating from either Pennsylvania or the surrounding states are significantly more likely to participate than those living in the eastern states (reference category). This probably reflects lower travel costs for people from Pennsylvania and its nearby states. On the contrary, the estimates associated with "Center", "Center East", "Center West", and "West" are all significantly negative, reflecting higher transportation costs for players from these states. USCF members who have actively played during the 12 months prior to the tournament are more likely to participate than those have not. Similarly, members who have played official games between 12 and 24 months before the World Open have a relatively higher participation rate. The variable "Chess age" is not significant, but its square does have a significant (and negative) effect: players who have had a USCF rating since a long time are less likely to come to a World Open. Since this variable is a proxy for age, this suggests that older chess players have lower participation rates. Finally, players with a provisory rating (those who have roughly played less than 25 games) are significantly less likely to participate. 
Table 5: Participation decision

\begin{tabular}{|c|c|c|c|c|c|}
\hline Variable & I & II & III & IV & $\mathrm{V}$ \\
\hline $0 \leq r<20$ & $\begin{array}{r}-0.234^{* *} \\
(0.05)\end{array}$ & $\begin{array}{r}-0.314^{* *} \\
(0.05)\end{array}$ & $\begin{array}{r}-0.249^{* *} \\
(0.06)\end{array}$ & $\begin{array}{r}-0.255^{* *} \\
(0.06)\end{array}$ & $\begin{array}{r}-0.209^{* *} \\
(0.07)\end{array}$ \\
\hline $20 \leq r<40$ & $\begin{array}{r}-0.173^{* *} \\
(0.06)\end{array}$ & $\begin{array}{r}-0.223^{* *} \\
(0.06)\end{array}$ & $\begin{array}{r}-0.223^{* *} \\
(0.06)\end{array}$ & $\begin{array}{r}-0.188^{* *} \\
(0.07)\end{array}$ & $\begin{array}{r}-0.222^{* * *} \\
(0.07)\end{array}$ \\
\hline $40 \leq r<60$ & $\begin{array}{r}-0.188^{* *} \\
(0.06)\end{array}$ & $\begin{array}{r}-0.221^{* *} \\
(0.06)\end{array}$ & $\begin{array}{r}-0.192^{* *} \\
(0.06)\end{array}$ & $\begin{array}{r}-0.190^{* *} \\
(0.07)\end{array}$ & $\begin{array}{r}-0.173^{*} \\
(0.07)\end{array}$ \\
\hline $60 \leq r<80$ & $\begin{array}{r}-0.156^{* *} \\
(0.06)\end{array}$ & $\begin{array}{r}-0.173^{* *} \\
(0.06)\end{array}$ & $\begin{array}{r}-0.170^{* *} \\
(0.06)\end{array}$ & $\begin{array}{r}-0.146^{*} \\
(0.07)\end{array}$ & $\begin{array}{r}-0.166^{*} \\
(0.07)\end{array}$ \\
\hline $100 \leq r<120$ & $\begin{array}{r}-0.088 \\
(0.05)\end{array}$ & $\begin{array}{r}-0.079 \\
(0.05)\end{array}$ & $\begin{array}{r}0.027 \\
(0.06)\end{array}$ & $\begin{array}{c}-0.076 \\
(0.06)\end{array}$ & $\begin{array}{l}0.005 \\
(0.07)\end{array}$ \\
\hline $120 \leq r<140$ & $\begin{array}{l}0.101 \dagger \\
(0.05)\end{array}$ & $\begin{array}{r}0.124^{*} \\
(0.05)\end{array}$ & $\begin{array}{r}0.158^{* * *} \\
(0.06)\end{array}$ & $\begin{array}{r}0.098 \\
(0.06)\end{array}$ & $\begin{array}{l}0.118 \dagger \\
(0.07)\end{array}$ \\
\hline $140 \leq r<160$ & $\begin{array}{r}0.112^{*} \\
(0.06)\end{array}$ & $\begin{array}{r}0.145^{* *} \\
(0.06)\end{array}$ & $\begin{array}{r}0.212^{* * *} \\
(0.06)\end{array}$ & $\begin{array}{r}0.162^{*} \\
(0.07)\end{array}$ & $\begin{array}{r}0.200^{* * *} \\
(0.07)\end{array}$ \\
\hline $160 \leq r<180$ & $\begin{array}{r}0.258^{* *} \\
(0.05)\end{array}$ & $\begin{array}{r}0.315^{* *} \\
(0.06)\end{array}$ & $\begin{array}{r}0.373^{* *} \\
(0.06)\end{array}$ & $\begin{array}{r}0.281^{* *} \\
(0.07)\end{array}$ & $\begin{array}{r}0.326^{* *} \\
(0.07)\end{array}$ \\
\hline $180 \leq r<200$ & $\begin{array}{r}0.298^{* *} \\
(0.05)\end{array}$ & $\begin{array}{r}0.370^{* *} \\
(0.06)\end{array}$ & $\begin{array}{r}0.445^{* *} \\
(0.06)\end{array}$ & $\begin{array}{r}0.318^{* *} \\
(0.07)\end{array}$ & $\begin{array}{r}0.389^{* *} \\
(0.07)\end{array}$ \\
\hline $2000 \leq$ rating $<2200$ & & $\begin{array}{r}1.079^{* *} \\
(0.04)\end{array}$ & $\begin{array}{r}1.255^{* * *} \\
(0.04)\end{array}$ & $\begin{array}{r}1.080^{* * *} \\
(0.04)\end{array}$ & $\begin{array}{r}1.259^{* * *} \\
(0.04)\end{array}$ \\
\hline $1800 \leq$ rating $<2000$ & & $\begin{array}{r}0.679^{* *} \\
(0.03)\end{array}$ & $\begin{array}{r}0.806^{* *} \\
(0.04)\end{array}$ & $\begin{array}{r}0.680^{* *} \\
(0.03)\end{array}$ & $\begin{array}{r}0.808^{* *} \\
(0.04)\end{array}$ \\
\hline $1600 \leq$ rating $<1800$ & & $\begin{array}{r}0.295^{* *} \\
(0.03)\end{array}$ & $\begin{array}{r}0.357^{* *} \\
(0.04)\end{array}$ & $\begin{array}{r}0.295^{* *} \\
(0.03)\end{array}$ & $\begin{array}{r}0.357^{* *} \\
(0.04)\end{array}$ \\
\hline Pennsylvania & & & $\begin{array}{r}0.828^{* *} \\
(0.05)\end{array}$ & & $\begin{array}{r}0.828^{* *} \\
(0.05)\end{array}$ \\
\hline Surrounding states & & & $\begin{array}{r}0.595^{* *} \\
(0.03)\end{array}$ & & $\begin{array}{r}0.595^{* *} \\
(0.03)\end{array}$ \\
\hline Center & & & $\begin{array}{r}-1.047^{* *} \\
(0.05)\end{array}$ & & $\begin{array}{r}-1.046^{* *} \\
(0.05)\end{array}$ \\
\hline Center East & & & $\begin{array}{r}-0.458^{* *} \\
(0.05)\end{array}$ & & $\begin{array}{r}-0.457^{* *} \\
(0.05)\end{array}$ \\
\hline Center West & & & $\begin{array}{r}-1.290^{* * *} \\
(0.09)\end{array}$ & & $\begin{array}{r}-1.288^{* * *} \\
(0.09)\end{array}$ \\
\hline West & & & $\begin{array}{r}-1.300^{* * *} \\
(0.05)\end{array}$ & & $\begin{array}{r}-1.299^{* *} \\
(0.05)\end{array}$ \\
\hline Active last 12 months & & & $\begin{array}{r}1.514^{* *} \\
(0.05)\end{array}$ & & $\begin{array}{r}1.510^{* * *} \\
(0.05)\end{array}$ \\
\hline Active last $13-24$ months & & & $\begin{array}{r}0.545^{* *} \\
(0.04)\end{array}$ & & $\begin{array}{r}0.540^{* * *} \\
(0.04)\end{array}$ \\
\hline Chess age in months & & & $\begin{array}{r}0.001 \\
(0.00)\end{array}$ & & $\begin{array}{r}0.001 \\
(0.00)\end{array}$ \\
\hline (Chess age in months) $^{2}$ & & & $\begin{array}{r}-0.000^{* *} \\
(0.00)\end{array}$ & & $\begin{array}{r}-0.000^{* *} \\
(0.00)\end{array}$ \\
\hline Rating Trend & & & $\begin{array}{r}0.006^{* *} \\
(0.00)\end{array}$ & & $\begin{array}{r}0.006^{* *} \\
(0.00)\end{array}$ \\
\hline$\left(_{\text {Rating Trend }}{ }^{2}\right.$ & & & $\begin{array}{r}-0.000^{* *} \\
(0.00)\end{array}$ & & $\begin{array}{r}-0.000^{* *} \\
(0.00)\end{array}$ \\
\hline Provisory rating & & & $-1.701^{* *}$ & & $\begin{array}{r}-1.717^{* * *} \\
(0.14)\end{array}$ \\
\hline$(0 \leq r<20) \times[2006,2008]$ & & & & $\begin{array}{r}-0.126 \\
(0.09)\end{array}$ & $\begin{array}{r}-0.111 \\
(0.09)\end{array}$ \\
\hline$(20 \leq r<40) \times[2006,2008]$ & & & & $\begin{array}{r}-0.029 \\
(0.09)\end{array}$ & $\begin{array}{l}0.046 \\
(0.10)\end{array}$ \\
\hline$(40 \leq r<60) \times[2006,2008]$ & & & & $\begin{array}{r}-0.015 \\
(0.09)\end{array}$ & $\begin{array}{r}-0.025 \\
(0.10)\end{array}$ \\
\hline$(60 \leq r<80) \times[2006,2008]$ & & & & 0.002 & 0.037 \\
\hline$(80 \leq r<100) \times[2006,2008]$ & & & & $\begin{array}{r}0.105 \\
(0.09)\end{array}$ & 0.050 \\
\hline$(100 \leq r<120) \times[2006,2008]$ & & & & 0.095 & 0.136 \\
\hline$(120 \leq r<140) \times[2006,2008]$ & & & & $\begin{array}{r}(0.08) \\
0.199^{*} \\
(0.08)\end{array}$ & $\begin{array}{l}(0.09) \\
0.198^{*} \\
(0.09)\end{array}$ \\
\hline$(140 \leq r<160) \times[2006,2008]$ & & & & $\begin{array}{r}0.040 \\
(0.09)\end{array}$ & $\begin{array}{r}0.098 \\
(0.09)\end{array}$ \\
\hline$(160 \leq r<180) \times[2006,2008]$ & & & & $\begin{array}{r}0.225^{* *} \\
(0.08)\end{array}$ & $\begin{array}{r}0.216^{*} \\
(0.09)\end{array}$ \\
\hline$(180 \leq r<200) \times[2006,2008]$ & & & & $\begin{array}{r}0.285^{* *} \\
(0.08)\end{array}$ & $\begin{array}{r}0.252^{* *} \\
(0.09)\end{array}$ \\
\hline Constant & $\begin{array}{r}-3.254^{* *} \\
(0.04)\end{array}$ & $\begin{array}{r}-3.660^{* *} \\
(0.04)\end{array}$ & $\begin{array}{r}-5.138^{* *} \\
(0.09)\end{array}$ & $\begin{array}{r}-3.688^{* *} \\
(0.05)\end{array}$ & $\begin{array}{r}-5.140^{* *} \\
(0.10)\end{array}$ \\
\hline
\end{tabular}




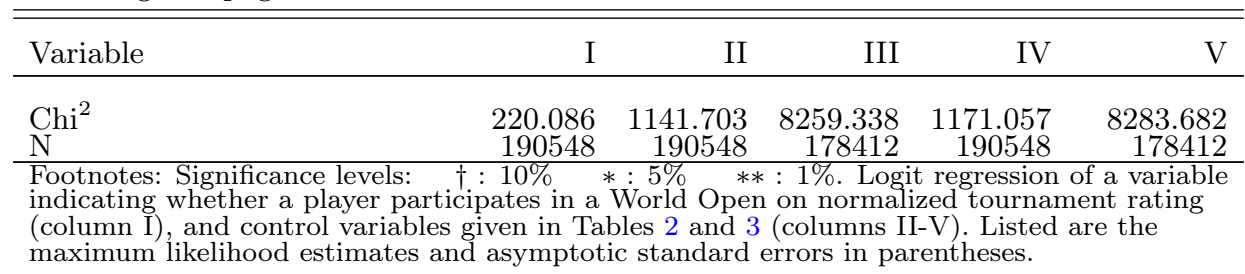

\subsection{Relative performance}

We now turn to testing whether the results on game outcomes are compatible with our prediction that the expected strength-shock among participants, $\widehat{\varepsilon}(r)$, decreases with $r$. To do this, we regress the outcome of a game on a function of each player's rating that encompasses Elo's winning expectancy formula as a special case, and check whether the parameters in the model are equal to zero (corresponding to the case where $\widehat{\varepsilon}(r)$ is invariant with $r$ ), or take certain specific values (compatible with the expected shock being a decreasing function of the rating).

The game outcome when player $i$ faces $j$ is still denoted as $\mathrm{RES}_{i j}, r_{i}$ and $r_{j}$ are these players' reference ratings, $\varepsilon_{i}$ and $\varepsilon_{j}$ their strength-shocks, and Elo's winning expectancy is $\mathrm{WE}_{i j}$ (for notational simplicity we suppress the indices for tournament rounds and years). We thus have

$$
\mathrm{WE}_{i j}=\left(1+10^{-\left(r_{i}-r_{j}\right) / 400}\right)^{-1} .
$$

The expected game outcome between the two players, given their ratings and strengthshocks, is

$$
E\left(\mathrm{RES}_{i j} \mid r_{i}, r_{j}, \varepsilon_{i}, \varepsilon_{j}\right)=\left(1+10^{-\left(r_{i}+\varepsilon_{i}-r_{j}-\varepsilon_{j}\right) / 400}\right)^{-1},
$$

which is Elo's winning expectancy formula evaluated at $r_{i}+\varepsilon_{i}$ and $r_{j}+\varepsilon_{j}$. It should be emphasized that in the above expression the shocks $\varepsilon_{i}$ and $\varepsilon_{j}$ are unobserved. But Proposition 2 tells us how the expectation of these shocks vary with $r$.

To make our test operational, we need to express the expected outcome as a linear function of the shocks. We therefore take a first-order Taylor expansion of the right-hand side of (7) around $\varepsilon_{i}-\varepsilon_{j}=0$ :

$$
E\left(\mathrm{RES}_{i j} \mid r_{i}, r_{j}, \varepsilon_{i}, \varepsilon_{j}\right) \simeq \mathrm{WE}_{i j}+\left[\frac{\log (10)}{400} \mathrm{WE}_{i j}\left(1-\mathrm{WE}_{i j}\right)\right]\left(\varepsilon_{i}-\varepsilon_{j}\right) .
$$

Taking expectations with respect to $\varepsilon_{i}$ and $\varepsilon_{j}$, conditional on $r_{i}$ and $r_{j}$, gives

$$
E\left(\mathrm{RES}_{i j} \mid r_{i}, r_{j}\right) \simeq \mathrm{WE}_{i j}+\left[\frac{\log (10)}{400} \mathrm{WE}_{i j}\left(1-\mathrm{WE}_{i j}\right)\right] E\left(\varepsilon_{i}-\varepsilon_{j} \mid r_{i}, r_{j}\right) .
$$

Next we make the simplifying assumption that the expectation of the difference in shocks is constant within bins to which the ratings belong. More precisely, it is assumed that

$$
E\left(\varepsilon_{i}-\varepsilon_{j} \mid r_{i} \in[20(k-1), 20 k), r_{j} \in[20(l-1), 20 l)\right)=\beta_{k l}, \text { for } k, l=1, \ldots, 10 .
$$

Each $\beta_{k l}$ can be interpreted as an average rating adjustment necessary to account for selective participation in the tournament: if the representative player $i$ in the $k$-th bin plays against the representative player $j$ in the $l$-th bin, then the two players perform as if their rating difference is not $r_{i}-r_{j}$ but $r_{i}-r_{j}+\beta_{k \ell}$. So if $\beta_{k \ell}$ is positive (resp. negative) player $i$ performs better (resp. worse) than what would be predicted by Elo's winning expectancy. Only after adjusting the difference in ratings by $\beta_{k \ell}$ points does the Elo formula correctly measure the expected 
game outcome between the two representative players. Note that our assumption on the shocks implies $\beta_{k l}=-\beta_{l k}$, i.e., in absolute values the matrix of $\beta$ 's is symmetric.

Taking $\mathrm{WE}_{i j}$ to the left-hand side of (8), substituting expression (9), we get the (approximate) regression function

$$
\begin{aligned}
\mathrm{RES}_{i j}-\mathrm{WE}_{i j}= & {\left[\frac{\log (10)}{400} \mathrm{WE}_{i j}\left(1-\mathrm{WE}_{i j}\right)\right] } \\
& \times \sum_{k=1}^{10} \sum_{l=1}^{10} \beta_{k l} \times 1\left\{r_{i} \in[20(k-1), 20 k), r_{j} \in[20(l-1), 20 l)\right\}+v_{i j}
\end{aligned}
$$

where, by construction, the error term $v_{i j}$ satisfies the zero-conditional-mean assumption, i.e., $E\left(v_{i j} \mid r_{i}, r_{j}\right)=0$.

When $\widehat{\varepsilon}(r)$ is invariant with $r$, all $\beta$ s should be zero. This corresponds to the case where expected game outcomes are adequately modeled by Elo's winning expectancy formula. When $\widehat{\varepsilon}(r)$ varies with $r$, we only expect that $\beta_{k l}=0$ for all $k=l$ (players whose ratings are in the same bin have the same expected shock, and hence Elo's formula should coincide with expected game outcomes). All other parameters should be different from zero. When, as we intuitively expect, $\widehat{\varepsilon}(r)$ decreases for all $r$, we should find that for all $k<l: \beta_{k l}>0$, and $\beta_{k l}$ increases with $k$. By symmetry, we should similarly have that for all $k>l: \beta_{k l}<0$, and $\beta_{k l}$ decreases in $k$.

Regression model (10) is estimated by pooling together all matches from all rounds, sections, and years. ${ }^{26}$ Table 6 reports the estimation results. It gives the OLS estimates of $\beta_{k \ell}$, for all $k<l$ (the upper half of the matrix of $\beta \mathrm{s}$ ), and the usual standard error in parentheses. For instance, the estimate of $\beta_{16}$ equals 35.778 and its standard error is 10.28 (significant at the $1 \%$ level), implying that when the representative player with a normalized reference rating between 0 and 20 plays against a representative player with rating between 100 and 120, the former performs as if his true strength level is 35 Elo points higher. Put differently, to account for self-selection on strength shocks, the difference in ratings between the two players requires an adjustment of 35 points. Table 6 shows first of all that all diagonal element $\beta_{k k}$ are not statistically significant. This is as expected: if two players from the same Elo bin face each other, their strength shocks are identical on average, and hence the expected outcome of their game equals the winning expectancy (1). The off-diagonal elements are often significant (especially when $k$ and $\ell$ are far apart). The estimates suggest that relatively to the Elo winning expectancy, players near the upper bound of a section play less well than players near the lower bound of the section. Whenever a given line in the table has multiple significant estimates, these estimates are generally ordered in the expected way (increasing as one reads from left to right). When we test the null hypothesis that $\beta_{k \ell}=0$, for all $k<l$ (55 restrictions) with a standard F-test, we find that the outcome of the F-statistic is 2.99 . The $5 \%$ critical value of a $\mathrm{F}$ distribution with 55 and 24,520 (24,575-55) degrees of freedom being 1.33, we reject the null at the $5 \%$ level. Overall the results of Table 6 suggest that the expected unobserved strength-shock is lower for highly rated players than for lowly rated players, i.e., $\widehat{\varepsilon}(r)$ decreases with $r$.

\footnotetext{
${ }^{26}$ Each given game, however, appears only once in the estimation sample. Including each game twice (once viewed from $i$ 's viewpoint and once from $j$ 's) would have artificially decreased all standard errors and augmented all t-statistics. Furthermore, for each game, player $i$ is chosen to be the player with the lowest normalized reference rating, and $j$ the one with the highest. This implies that we can only identify and estimate $\beta_{k \ell}$, for all $k<l$. Determining player $i$ and player $j$ randomly, and imposing the symmetry condition $\beta_{k l}=-\beta_{l k}$, would lead to similar estimates.
} 


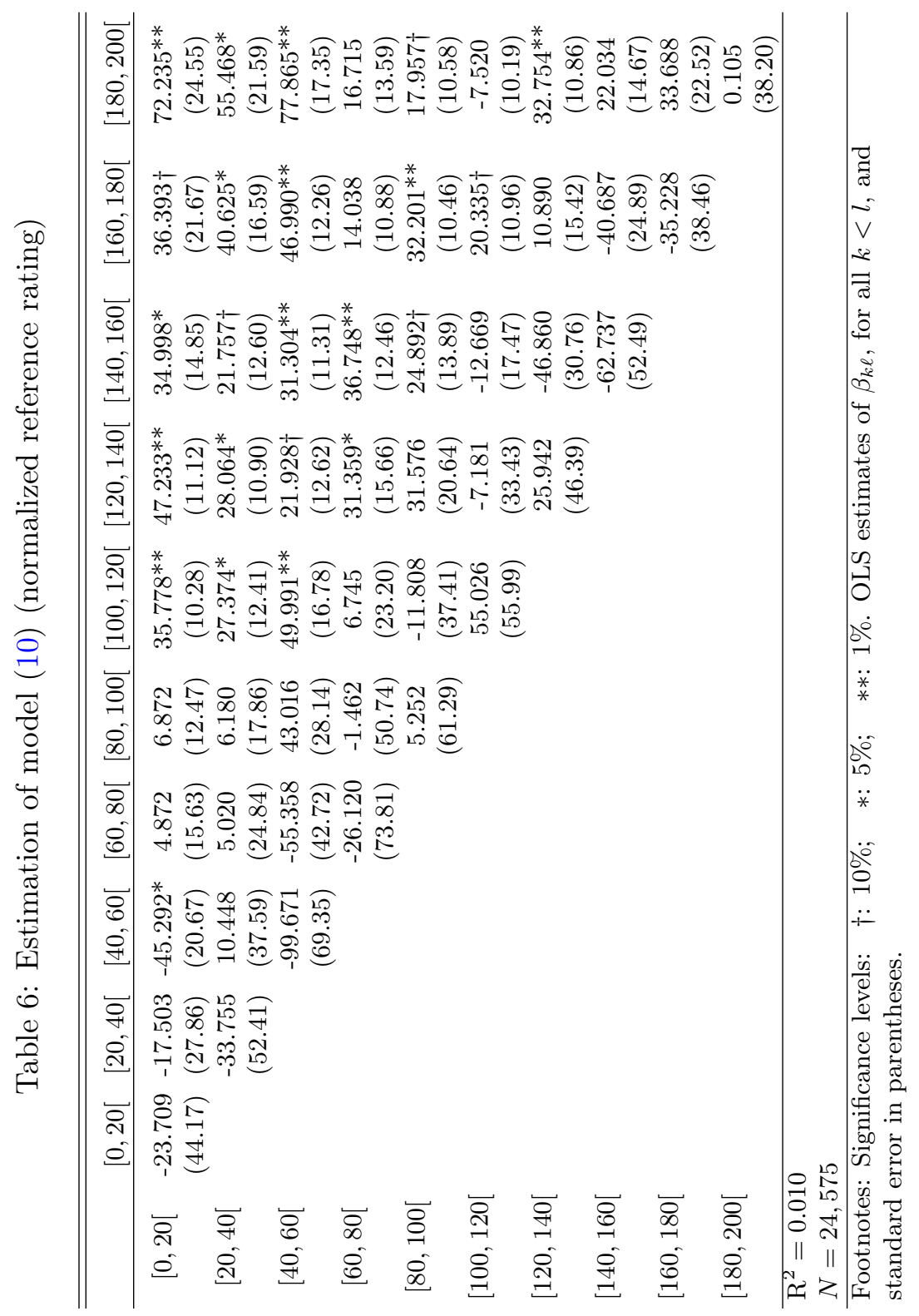




\section{Robustness analysis}

In this section we study the robustness of our results. First, we apply the methodology to data from another chess championship, the Paris Chess Tournament. This tournament is quite similar to the World Open except that prizes and entry fees are significantly lower. By comparing the two tournaments, we thus analyze to what extent the results reported sofar change when the monetary incentives are mild. Second, we report estimations for alternative specifications of model (10).

\subsection{Application to the Paris Chess tournament}

The Paris Chess Tournament (Championnat International de Paris Ille-De-France) is organized each year in July. This tournament is structured like the World Open: it is a Swiss tournament, participants may play nine rounds (or less), and compete with each other in different sections. Unlike the World Open, there are, however, only four sections: 'Open FIDE' for players whose Elo ranking is above 2,200; 'Open A' for players ranked between 1,800 and 2,300; 'Open B' for players between 1,400 and 1,900; and 'Open C' for players under 1,500. Given that there are less sections, the range of Elo rankings in each section is mechanically larger in the Paris tournament. Note that there is some overlap between the sections, giving players in certain Elo intervals the choice between two sections. Players with a rating between 1,800 and 1,900, for instance, have the possibility to play in either Open A or Open B. Those who opt for Open B play in their natural section, and those who opt for Open A play above their natural section. Like in the World Open, players in the Paris tournament can thus choose between playing in their own section or in a higher more competitive one.

The striking difference between the two tournaments lies in their prize structure: awarded prizes are much lower in Paris. For example, in 2012, the winner of Open A could only win $€ 1,500$, and the winner of Open $\mathrm{B} € 1,000$. This is about one tenth of the amounts awarded in the World Open. ${ }^{27}$ Consequently, the function $G$ (expected prize amount) should be a relatively flatter function of $r$ in the Paris tournament. We conjecture that the auto-selection effects observed in the World Open, should be less strong or absent in the Paris tournament. Players primarily decide to participate depending on their intrinsic motivation (the $u_{i}$ term in our model).

To verify this prediction, ${ }^{28}$ we estimate a model analogous to model (10) using data on all games played in Open A and Open B of the Paris tournament between 2001 and 2013. Like we did in the case of the World Open, we restrict the analysis to players who participated in their natural sections. Thus among participants in Open A we only kept those rated between 1,900 and 2,300; similarly, among participants in Open B we only kept those with a rating between 1,500 and 1,900. With this elimination both sections have the same width of 400 Elo points. As in the case of the World Open we define 10 bins for each section, so that each bin now covers an interval of 40 Elo points (instead of 20 in the World Open). The model we estimate is

$$
\begin{aligned}
\mathrm{RES}_{i j}-\mathrm{WE}_{i j}= & {\left[\frac{\log (10)}{400} \mathrm{WE}_{i j}\left(1-\mathrm{WE}_{i j}\right)\right] } \\
& \times \sum_{k=1}^{10} \sum_{l=1}^{10} \beta_{k l} \times 1\left\{r_{i} \in[40(k-1), 40 k), r_{j} \in[40(l-1), 40 l)\right\}+v_{i j}
\end{aligned}
$$

The results are in Table A.6. The presentation is as in Table 6, i.e., we give the OLS estimates of $\beta_{k \ell}$, for all $k<l$, and the standard errors in parentheses. The parameter $\beta_{k \ell}$ is now associated

\footnotetext{
${ }^{27}$ Registration fees are also lower in the Paris tournament, around $€ 70$.

${ }^{28}$ We do not have data on the full population of French chess players. We cannot therefore analyze the decision to participate in the Paris tournament, i.e., estimate the analogue of the logit model (6).
} 
with the indicator that player $i$ is rated between $40(k-1)$ and $40 k$, and player $j$ between $40(l-1)$ and $40 l$.

Table A.6 shows that only a few $\beta$ s are statistically different from zero. Whereas in the case of the World Open (Table 6) 17 parameters out of 55 are significant at the 1 or $5 \%$ level, in the case of the Paris tournament the null hypothesis can be rejected just 6 times (of which 3 times only at the $10 \%$ level). Performing the F-test of the null hypothesis that the $\beta$ s equal zero, the F-statistic now equals 0.98 . The $5 \%$ critical value of the F-distribution with 55 and 4,665 degrees of freedom is 1.34 , so the null hypothesis cannot be rejected this time. Overall the results for the Paris tournament are supportive of the idea that self-selection on strength shocks should matter less when monetary incentives are mild.

\subsection{Other specifications}

In Table 6 we reported estimates of regression model (10) by defining the regressor $r$ as the normalized reference rating. This is a natural choice as chess players most likely make their participation decision on the basis of this value of the Elo rating (see Section 3.2). An alternative is to use the tournament rating as the explanatory variable. The advantage of this variable is that it better reflects the strength of players at the start of tournament, at least for those who have played games shortly before the World Open. The results are in Table A.7. To simplify the comparison with Table 6 , we estimate the model only on players whose normalized tournament rating is between 0 and 200. The results in the two tables are quite similar: about the same number of significant parameters, same signs of the estimates. Only the magnitudes of the estimates differ somewhat, but this is not surprising as the interpretation of the strength shock in not the same in the two models. ${ }^{29}$ Regarding the implications of the results, it apparently does not really matter whether the reference or tournament rating is used as the explanatory variable in model (10). We experimented with several other specifications as well (different sizes of the bins, estimation per round, etc.) but again the results ${ }^{30}$ do not alter our conclusions.

\section{Concluding remarks}

In this paper we have studied the participation decisions of amateur chess players in the World Open, a large chess tournament held in the USA. We have also analyzed how players perform in this tournament (conditional on their decision to participate). In terms of the size of the prize budget, the World Open is among the most generous tournaments in the world, and it therefore attracts many competitors each year. Using an exhaustive data set on all players registered with the U.S. Chess federation, we find that those with an Elo rating near the top of the section in which they can compete are over-represented at the World Open (relatively to the number of players with similar ratings in the population of U.S. chess players), while those near the bottom are under-represented. We furthermore find that the over-representation of highly rated players is accentuated in years where awarded prizes are higher. These results are quite intuitive and natural, and reflect that chess players with relatively high ratings have larger expected benefits, and hence they have stronger incentives to participate.

Our results regarding the chess performance of players are less intuitive. Regressing the game outcomes on a specific function of the two opponents' Elo ratings, we find evidence against the hypothesis that the expected score can be adequately modeled by Elo's winning expectancy formula. Instead the estimates suggest that highly (resp. lowly) rated players

\footnotetext{
${ }^{29}$ In the model underlying Table $6, \varepsilon$ is the deviation between the true chess strength during the World Openand the reference rating, while in the model underlying Table A.7 it represents the deviation between true strength and the tournament rating.

${ }^{30}$ The additional results can be obtained from the authors upon request.
} 
under-perform (resp. over-perform) relatively to what would be predicted by this formula. As shown in our theoretical model, this is compatible (under certain technical conditions) with players self-selecting into the tournament on the basis of their unobserved strength shocks: the average strength shock is larger among lowly-rated participants than among highly-rated participants, resulting in over-performance of the former and under-performance of the latter.

Although the chess competition that we have studied is admittedly just a specific example of a tournament, the findings of this paper may have external validity as well. As mentioned in the introduction, many firms compensate their employees using pay schemes that are structured as tournaments. If such firm advertise job openings, only workers for whom the expected benefits of applying (which depends among other things on the level of salaries and the probability of getting hired) exceed the costs (sending a resume, travel costs, the emotional costs of attending the interviews) will apply. Very much like in our chess tournament, the pool of applicants will therefore be a self-selected group of employees. This self-selection may affect the hiring process, and ultimately the observed production levels.

So far our theoretical model has only been used to obtain predictions on participation decisions and on game outcomes. It would also be interesting to actually estimate the model. This would first of all require a study of the conditions under which the model parameters (the expected prize amount function and the joint distribution of strength shocks and net private benefits) are identified. Next it would require the development of methods for estimating these parameters. We leave these challenging research questions for future work. 


\section{References}

Ghazala Azmat and Marc Möller. Competition among Contests. RAND Journal of Economics, 40(4):743-768, Winter 2009.

Mark Bagnoli and Ted Bergstrom. Log-concave probability and its applications. Economic Theory, 26(2):445-469, August 2005.

Jennifer Brown. Quitters Never Win: The (Adverse) Incentive Effects of Competing with Superstars. Journal of Political Economy, 119(5):982-1013, October 2011.

Bentley Coffey and M. T. Maloney. The Thrill of Victory: Measuring the Incentive to Win. Journal of Labor Economics, 28(1):87-112, January 2010.

Ettore Damiano, Li Hao, and Wing Suen. First in Village or Second in Rome? International Economic Review, 51(1):263-288, February 2010.

Ettore Damiano, Li Hao, and Wing Suen. Competing for talents. Journal of Economic Theory, 147(6):2190-2219, November 2012.

Anna Dreber, Christer Gerdes, and Patrik Gränsmark. Beauty queens and battling knights: Risk taking and attractiveness in chess. Journal of Economic Behavior $\mathscr{E}$ Organization, 90: $1-18,2013$.

Ronald G. Ehrenberg and Michael L. Bognanno. Do Tournaments Have Incentive Effects? Journal of Political Economy, 98(6):1307-24, December 1990.

Arpad E. Elo. The Rating of Chessplayers (pastEpresent). Ishi Press International (2nd edition 2008), 1978.

Tor Eriksson. Executive Compensation and Tournament Theory: Empirical Tests on Danish Data. Journal of Labor Economics, 17(2):262-280, April 1999.

Christer Gerdes and Patrik Gränsmark. Strategic behavior across gender: A comparison of female and male expert chess players. Labour Economics, 17:766-775, 2010.

Mark Glickman. A Comprehensive Guide to Chess Ratings. American Chess Journal, 3:59-102, 1995.

Patrik Gränsmark. Masters of our time: Impatience and self-control in high-level chess games. Journal of Economic Behavior \& Organization, 82:179-191, 2012.

Jerry R. Green and Nancy L. Stokey. A Comparison of Tournaments and Contracts. Journal of Political Economy, 91(3):349-364, June 1983.

Kai Konrad. Strategy and Dynamics in Contests. Oxford University Press, 2009.

Edward P. Lazear. Performance Pay and Productivity. American Economic Review, 90(5): 1346-1361, December 2000.

Edward P. Lazear and Sherwin Rosen. Rank-Order Tournaments as Optimum Labor Contracts. Journal of Political Economy, 89(5):841-64, Oct. 1981.

Edwin Leuven, Hessel Oosterbeek, Joep Sonnemans, and Bas van der Klaauw. Incentives versus Sorting in Tournaments: Evidence from a Field Experiment. Journal of Labor Economics, 29(3):637-658, July 2011. 
Steven D. Levitt, John A. List, and Sally E. Sadoff. Checkmate: Exploring Backward Induction among Chess Players. American Economic Review, 101(2):975-990, April 2011.

Benny Moldovanu and Aner Sela. The Optimal Allocation of Prizes in Contests. American Economic Review, 91(3):542-558, June 2001.

Charles C. Moul and John V.C. Nye. Did the Soviets collude? A statistical analysis of championship chess 1940-1978. Journal of Economic Behavior $\&$ Organization, 70:10-21, 2009.

Roger B. Myerson and Karl Wärneryd. Population uncertainty in contests. Economic Theory, 27(2):469-474, February 2006.

Barry J. Nalebuff and Joseph E. Stiglitz. Prizes and Incentives: Towards a General Theory of Compensation and Competition. Bell Journal of Economics, 14(1):21-43, Spring 1983.

William E. Stein. Asymmetric rent-seeking with more than two contestants. Public Choice, 113(3/4):325-336, December 2002. 


\section{A Appendix}

\section{A.1 Geographic variables}

As explained in the main text, our data set records the states from which the chess players originate. The states are classified into seven groups, and we define the following seven indicator variables

- Center=1 if player originates from AR, IA, IL, KS, LA, MN, MO, ND, NE, OK, SD, TX, WI.

- Center East=1 if player originates from AL, IN, KY, MI, MS, OH, TN, WV.

- Center West=1 if player originates from AZ, CO, ID, MT, NM, UT, WY.

- East=1 if player originates from CT, FL, GA, MA, ME, NC, NH, RI, SC, VA, VT.

- Surrounding states=1 if player originates from DC, DE, NJ, NY, MD.

- Pennsylvania $=1$ if player originates from PA.

- West=1 if player originates from AK, CA, NV, OR, WA.

\section{A.2 Tables}

Table A.1: Number of distributed prizes per year and section

\begin{tabular}{ccccccccccccccc}
\hline \hline & 2001 & 2002 & 2003 & 2004 & 2005 & 2006 & 2007 & 2008 & 2009 & 2010 & 2011 & 2012 & Average \\
\hline U1600 & 23 & 20 & 20 & 22 & 28 & 42 & 26 & 34 & 13 & 23 & 17 & 15 & 24.0 \\
U1800 & 40 & 22 & 26 & 23 & 29 & 39 & 21 & 22 & 23 & 15 & 17 & 17 & 24.9 \\
U2000 & 32 & 20 & 20 & 35 & 35 & 26 & 21 & 34 & 21 & 21 & 20 & 28 & 25.9 \\
U2200 & 22 & 29 & 25 & 25 & 32 & 31 & 25 & 32 & 17 & 15 & 16 & 16 & 23.7 \\
Average & 29.7 & 22.3 & 22.7 & 26.1 & 31.0 & 34.2 & 22.9 & 30.1 & 18.9 & 18.4 & 17.6 & 19.8 & 24.7 \\
\hline \hline
\end{tabular}


Table A.2: Probability of winning a prize

\begin{tabular}{|c|c|c|c|c|c|c|}
\hline & All sections & All sections & U1600 & U1800 & U2000 & U2200 \\
\hline$r<0$ & $\begin{array}{c}-1.658^{* *} \\
(0.23)\end{array}$ & $\begin{array}{c}-1.659^{* *} \\
(0.23)\end{array}$ & $\begin{array}{c}-1.374^{* *} \\
(0.49)\end{array}$ & $\begin{array}{c}-0.961^{*} \\
(0.43)\end{array}$ & $\begin{array}{c}-2.636^{* *} \\
(0.75)\end{array}$ & $\begin{array}{c}-2.192^{* *} \\
(0.39)\end{array}$ \\
\hline $0 \leq r<20$ & $\begin{array}{c}-1.428^{* *} \\
(0.24)\end{array}$ & $\begin{array}{c}-1.368^{* *} \\
(0.24)\end{array}$ & $\begin{array}{c}-1.876^{*} \\
(0.76)\end{array}$ & $\begin{array}{c}-1.139^{*} \\
(0.53)\end{array}$ & $\begin{array}{c}-1.380^{* *} \\
(0.51)\end{array}$ & $\begin{array}{c}-1.457^{* *} \\
(0.38)\end{array}$ \\
\hline $20 \leq r<40$ & $\begin{array}{c}-0.769^{* *} \\
(0.21)\end{array}$ & $\begin{array}{c}-0.776^{* *} \\
(0.21)\end{array}$ & $\begin{array}{c}-1.591^{*} \\
(0.64)\end{array}$ & $\begin{array}{r}-0.501 \\
(0.45)\end{array}$ & $\begin{array}{r}-0.068 \\
(0.36)\end{array}$ & $\begin{array}{c}-1.417^{* *} \\
(0.39)\end{array}$ \\
\hline $40 \leq r<60$ & $\begin{array}{c}-0.631^{* *} \\
(0.19)\end{array}$ & $\begin{array}{c}-0.634^{* *} \\
(0.19)\end{array}$ & $\begin{array}{l}-0.058 \\
(0.40)\end{array}$ & $\begin{array}{l}-0.419 \\
(0.40)\end{array}$ & $\begin{array}{c}-0.699 \dagger \\
(0.40)\end{array}$ & $\begin{array}{c}-1.147^{* *} \\
(0.37)\end{array}$ \\
\hline $60 \leq r<80$ & $\begin{array}{c}-0.492^{* *} \\
(0.19)\end{array}$ & $\begin{array}{c}-0.496^{* *} \\
(0.19)\end{array}$ & $\begin{array}{l}-0.658 \\
(0.45)\end{array}$ & $\begin{array}{l}-0.300 \\
(0.41)\end{array}$ & $\begin{array}{l}-0.054 \\
(0.35)\end{array}$ & $\begin{array}{c}-1.073^{* *} \\
(0.36)\end{array}$ \\
\hline $100 \leq r<120$ & $\begin{array}{l}-0.022 \\
(0.16)\end{array}$ & $\begin{array}{l}0.026 \\
(0.16)\end{array}$ & $\begin{array}{l}0.049 \\
(0.36)\end{array}$ & $\begin{array}{l}0.140 \\
(0.34)\end{array}$ & $\begin{array}{l}-0.161 \\
(0.33)\end{array}$ & $\begin{array}{l}0.142 \\
(0.28)\end{array}$ \\
\hline $120 \leq r<140$ & $\begin{array}{c}0.432^{* *} \\
(0.15)\end{array}$ & $\begin{array}{c}0.408^{* *} \\
(0.15)\end{array}$ & $\begin{array}{l}0.403 \\
(0.32)\end{array}$ & $\begin{array}{l}0.526 \\
(0.32)\end{array}$ & $\begin{array}{l}0.694^{*} \\
(0.30)\end{array}$ & $\begin{array}{l}0.402 \\
(0.30)\end{array}$ \\
\hline $140 \leq r<160$ & $\begin{array}{c}0.627^{* *} \\
(0.15)\end{array}$ & $\begin{array}{c}0.627^{* *} \\
(0.15)\end{array}$ & $\begin{array}{l}0.600 \dagger \\
(0.31)\end{array}$ & $\begin{array}{l}0.434 \\
(0.33)\end{array}$ & $\begin{array}{c}1.092^{* *} \\
(0.29)\end{array}$ & $\begin{array}{l}0.682^{*} \\
(0.28)\end{array}$ \\
\hline $160 \leq r<180$ & $\begin{array}{c}0.729^{* *} \\
(0.14)\end{array}$ & $\begin{array}{c}0.699^{* *} \\
(0.15)\end{array}$ & $\begin{array}{l}0.446 \\
(0.32)\end{array}$ & $\begin{array}{l}0.712^{*} \\
(0.31)\end{array}$ & $\begin{array}{c}1.220^{* *} \\
(0.29)\end{array}$ & $\begin{array}{l}0.712^{*} \\
(0.29)\end{array}$ \\
\hline $180 \leq r<200$ & $\begin{array}{c}1.096^{* *} \\
(0.14)\end{array}$ & $\begin{array}{c}1.049^{* *} \\
(0.14)\end{array}$ & $\begin{array}{c}0.989^{* *} \\
(0.30)\end{array}$ & $\begin{array}{c}1.211^{* *} \\
(0.31)\end{array}$ & $\begin{array}{c}1.594^{* *} \\
(0.28)\end{array}$ & $\begin{array}{c}0.852^{* *} \\
(0.30)\end{array}$ \\
\hline $200 \leq r$ & $\begin{array}{c}1.146^{* *} \\
(0.15)\end{array}$ & $\begin{array}{c}1.113^{* *} \\
(0.16)\end{array}$ & $\begin{array}{c}1.250^{* *} \\
(0.31)\end{array}$ & $\begin{array}{c}1.489^{* *} \\
(0.33)\end{array}$ & $\begin{array}{c}1.758^{* *} \\
(0.35)\end{array}$ & $\begin{array}{c}1.099^{* *} \\
(0.42)\end{array}$ \\
\hline Constant & $\begin{array}{c}-2.088^{* *} \\
(0.12) \\
\end{array}$ & $\begin{array}{c}-1.907^{* *} \\
(0.17) \\
\end{array}$ & $\begin{array}{c}-1.850^{* *} \\
(0.34) \\
\end{array}$ & $\begin{array}{c}-1.838^{* *} \\
(0.35) \\
\end{array}$ & $\begin{array}{c}-2.328^{* *} \\
(0.38) \\
\end{array}$ & $\begin{array}{c}-1.321^{* *} \\
(0.41)\end{array}$ \\
\hline $\mathrm{Chi}^{2}$ & 629.459 & 751.359 & 209.015 & 186.960 & 305.398 & 265.551 \\
\hline $\mathrm{N}$ & 9538 & 9536 & 2295 & 2562 & 2632 & 2047 \\
\hline
\end{tabular}

Footnotes: Significance levels: $\dagger: 10 \% \quad *: 5 \% \quad * *: 1 \%$. Logit regression of a variable indicating whether a player has won a price on normalized tournament rating and control variables given in Tables 2 and 3 .

Listed are the maximum likelihood estimates and asymptotic standard errors in parentheses. 
Table A.3: Net gain of participating (prize won minus entry fee in $\$$ of 2012)

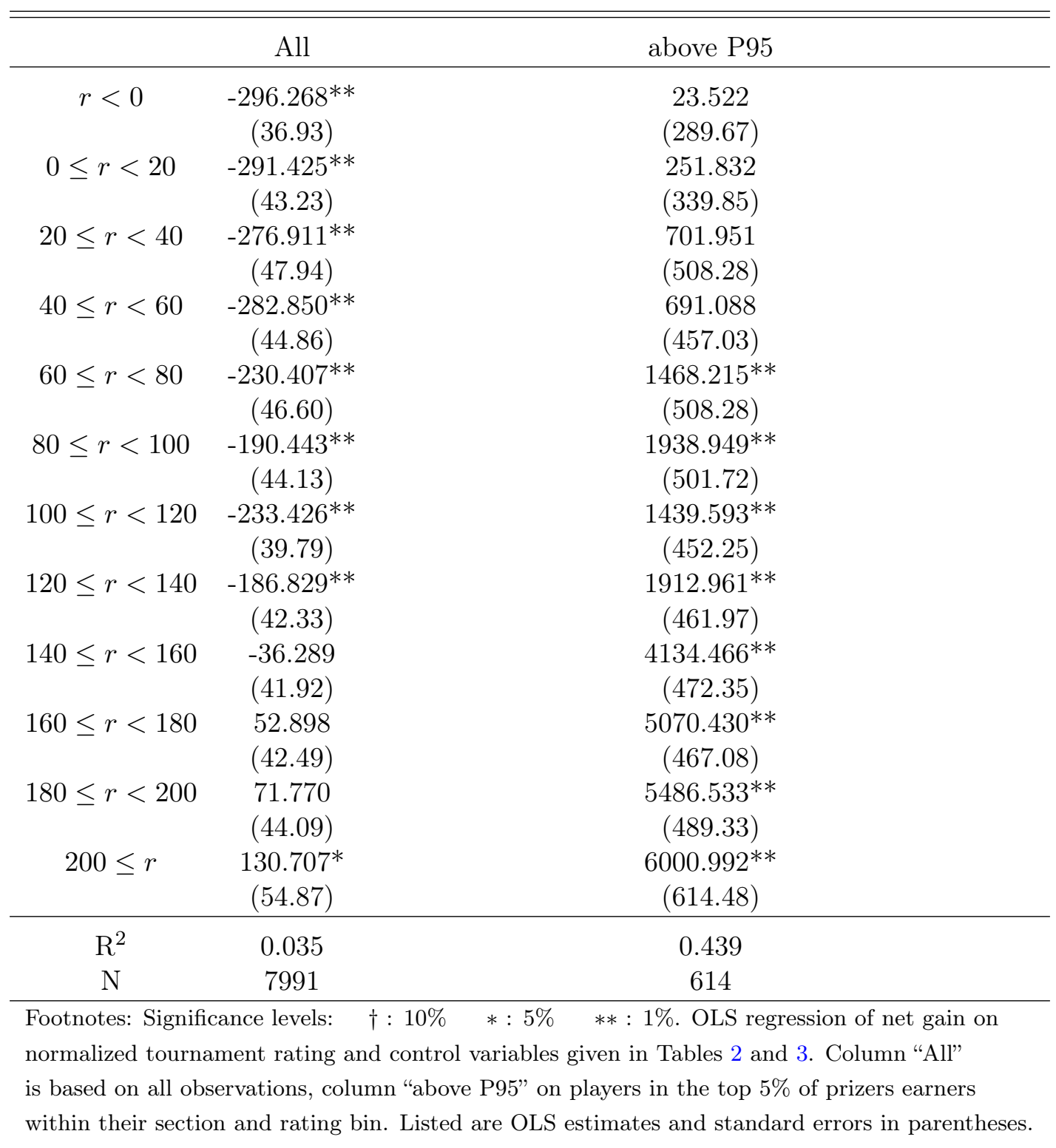


Table A.4: Final score after 9 rounds

\begin{tabular}{|c|c|c|c|c|c|}
\hline & All sections & U1600 & U1800 & U2000 & $\mathrm{U} 2200$ \\
\hline$r / 100$ & $\begin{array}{c}0.640^{* *} \\
(0.02)\end{array}$ & $\begin{array}{c}0.678^{* *} \\
(0.05)\end{array}$ & $\begin{array}{c}0.571^{* *} \\
(0.05)\end{array}$ & $\begin{array}{c}0.703^{* *} \\
(0.04)\end{array}$ & $\begin{array}{c}0.744^{* *} \\
(0.04)\end{array}$ \\
\hline$(r / 100)^{2}$ & $\begin{array}{c}0.054^{* *} \\
(0.01)\end{array}$ & $\begin{array}{c}0.031 \\
(0.02)\end{array}$ & $\begin{array}{c}0.080^{* *} \\
(0.03)\end{array}$ & $\begin{array}{c}0.100^{* *} \\
(0.02)\end{array}$ & $\begin{array}{c}0.108^{* *} \\
(0.02)\end{array}$ \\
\hline Constant & $\begin{array}{c}4.260^{* *} \\
(0.18)\end{array}$ & $\begin{array}{c}3.967^{* *} \\
(0.32)\end{array}$ & $\begin{array}{c}3.783^{* *} \\
(0.37)\end{array}$ & $\begin{array}{c}4.885^{* *} \\
(0.37)\end{array}$ & $\begin{array}{l}5.241^{*} \\
(0.40)\end{array}$ \\
\hline $\mathrm{R}^{2}$ & 0.268 & 0.310 & 0.248 & 0.304 & 0.409 \\
\hline $\mathrm{N}$ & 4672 & 1097 & 1285 & 1319 & 971 \\
\hline
\end{tabular}


Table A.5: Rating Gain

\begin{tabular}{|c|c|c|c|}
\hline & (I) & (II) & (III) \\
\hline$r<0$ & $\begin{array}{c}14.631^{* *} \\
(1.87)\end{array}$ & $\begin{array}{c}13.889^{* *} \\
(1.87)\end{array}$ & $\begin{array}{c}17.720^{* *} \\
(2.45)\end{array}$ \\
\hline $0 \leq r<20$ & $\begin{array}{c}6.912^{* *} \\
(2.00)\end{array}$ & $\begin{array}{c}8.067^{* *} \\
(1.98)\end{array}$ & $\begin{array}{c}8.225^{* *} \\
(2.65)\end{array}$ \\
\hline $20 \leq r<40$ & $\begin{array}{l}0.611 \\
(2.11)\end{array}$ & $\begin{array}{l}0.223 \\
(2.09)\end{array}$ & $\begin{array}{l}3.463 \\
(2.83)\end{array}$ \\
\hline $40 \leq r<60$ & $\begin{array}{l}4.187^{*} \\
(2.05)\end{array}$ & $\begin{array}{l}3.515 \dagger \\
(2.02)\end{array}$ & $\begin{array}{l}4.254 \\
(2.67)\end{array}$ \\
\hline $60 \leq r<80$ & $\begin{array}{l}0.596 \\
(2.08)\end{array}$ & $\begin{array}{l}0.117 \\
(2.06)\end{array}$ & $\begin{array}{l}0.757 \\
(2.71)\end{array}$ \\
\hline $80 \leq r<100$ & $\begin{array}{l}2.002 \\
(2.04)\end{array}$ & $\begin{array}{l}0.919 \\
(2.01)\end{array}$ & $\begin{array}{l}3.352 \\
(2.64)\end{array}$ \\
\hline $120 \leq r<140$ & $\begin{array}{l}-2.082 \\
(1.98)\end{array}$ & $\begin{array}{c}-3.423 \dagger \\
(1.95)\end{array}$ & $\begin{array}{l}-1.910 \\
(2.53)\end{array}$ \\
\hline $140 \leq r<160$ & $\begin{array}{c}-3.530 \dagger \\
(1.96)\end{array}$ & $\begin{array}{l}-4.858^{*} \\
(1.94)\end{array}$ & $\begin{array}{r}-2.842 \\
(2.53)\end{array}$ \\
\hline $160 \leq r<180$ & $\begin{array}{l}-4.950^{*} \\
(1.98)\end{array}$ & $\begin{array}{c}-6.962^{* *} \\
(1.96)\end{array}$ & $\begin{array}{l}-3.478 \\
(2.56)\end{array}$ \\
\hline $180 \leq r<200$ & $\begin{array}{l}-1.984 \\
(2.01)\end{array}$ & $\begin{array}{c}-4.300^{*} \\
(1.99)\end{array}$ & $\begin{array}{l}-2.007 \\
(2.59)\end{array}$ \\
\hline $200 \leq r$ & $\begin{array}{c}-10.148^{* *} \\
(2.32)\end{array}$ & $\begin{array}{c}-11.817^{* *} \\
(2.33)\end{array}$ & $\begin{array}{c}-10.220^{* *} \\
(2.96)\end{array}$ \\
\hline Constant & $\begin{array}{c}4.032^{* *} \\
(1.36)\end{array}$ & $\begin{array}{c}16.360^{* *} \\
(2.27)\end{array}$ & $\begin{array}{c}22.948^{* *} \\
(2.99)\end{array}$ \\
\hline $\mathrm{R}^{2}$ & 0.022 & 0.054 & 0.062 \\
\hline $\mathrm{N}$ & 9044 & 9044 & 5933 \\
\hline \multicolumn{4}{|c|}{$\begin{array}{l}\text { Footnotes: Significance levels: } \dagger: 10 \% \quad *: 5 \% \quad * *: 1 \% \text {. OLS regression } \\
\text { of rating gain (defined by equation (2)) on normalized tournament rating (column I). } \\
\text { Column II (full sample) and III (only players having played } 9 \text { rounds) give } \\
\text { results with controls. Listed are OLS estimates and standard errors in parentheses. }\end{array}$} \\
\hline
\end{tabular}




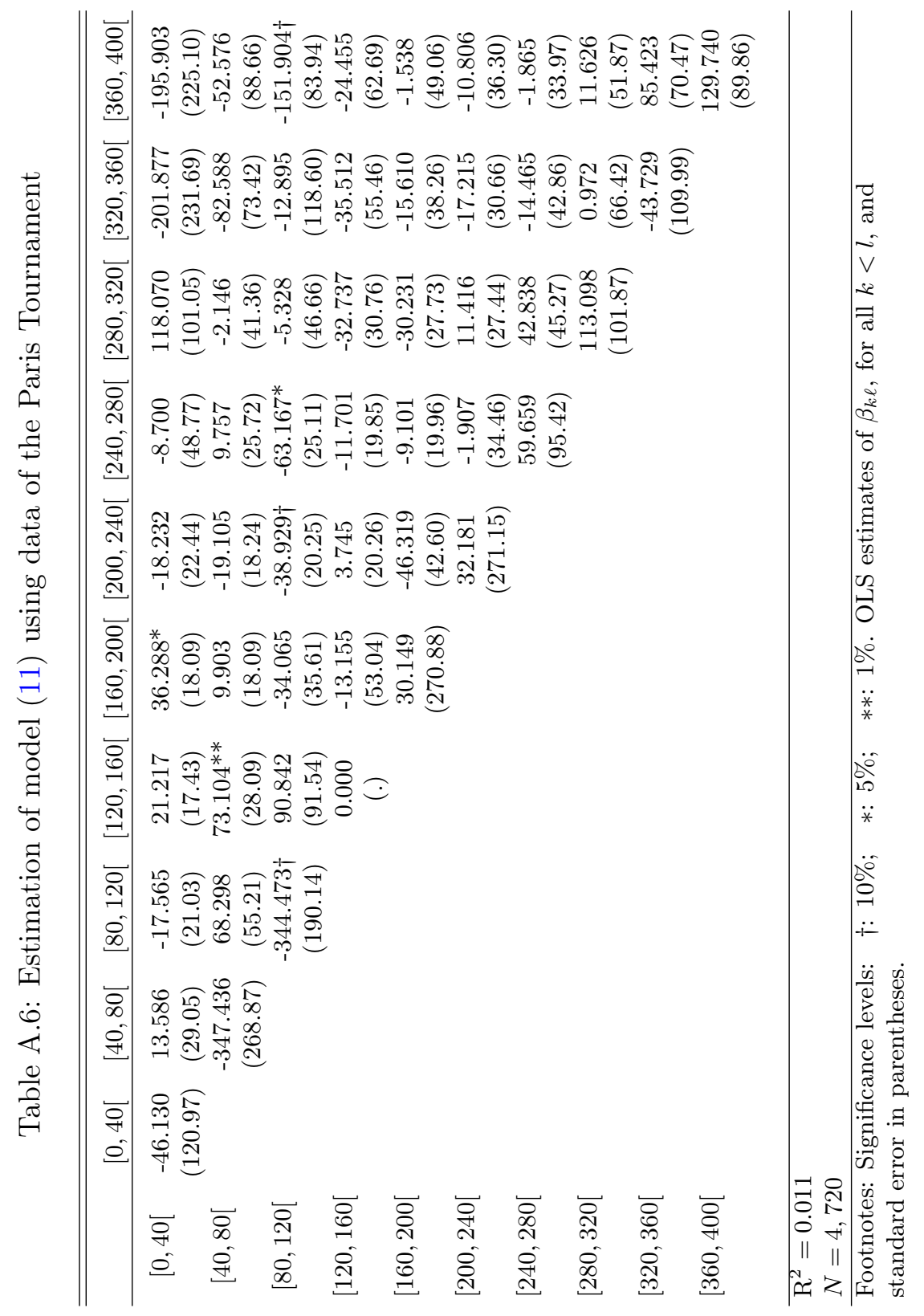




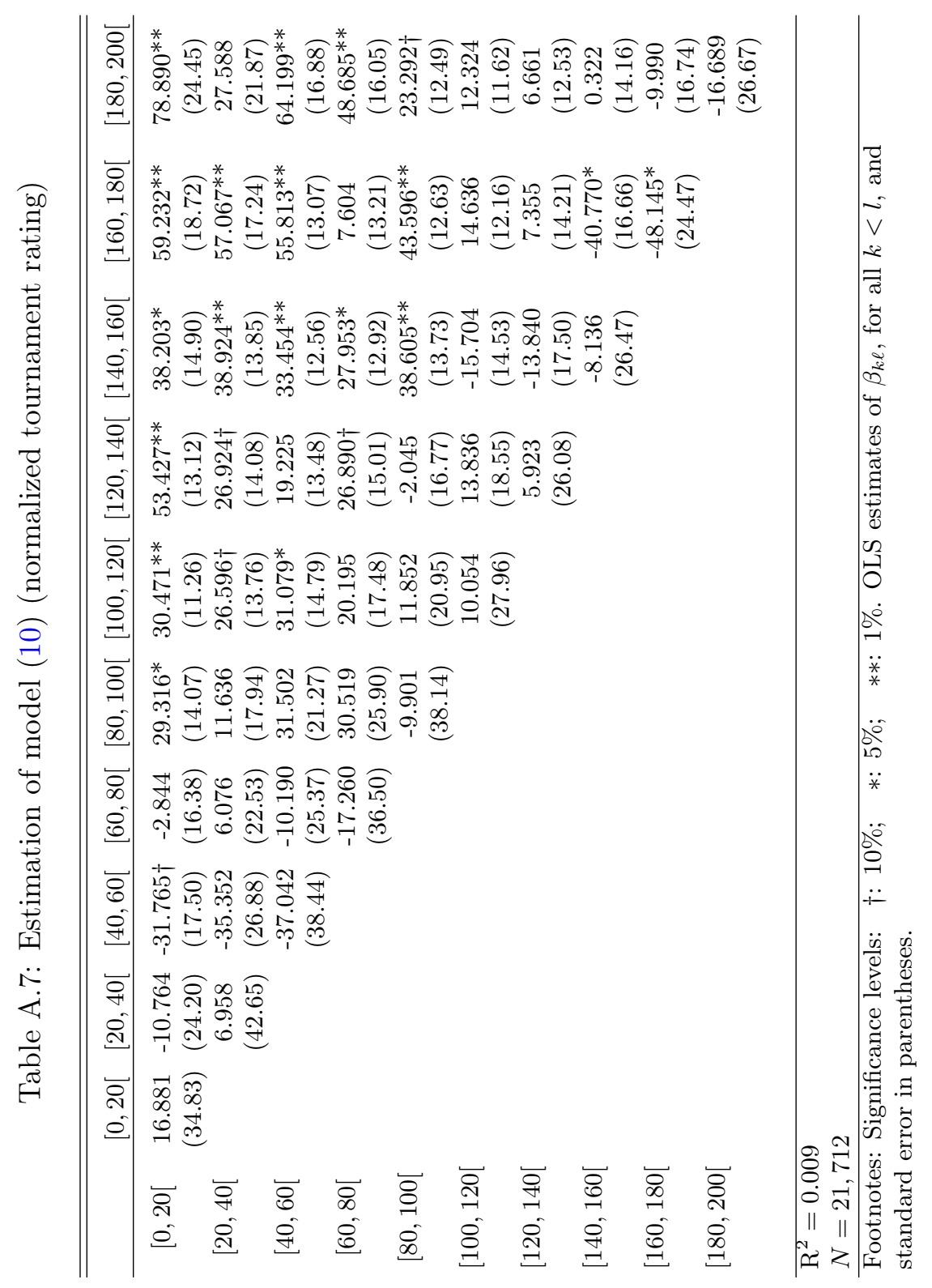




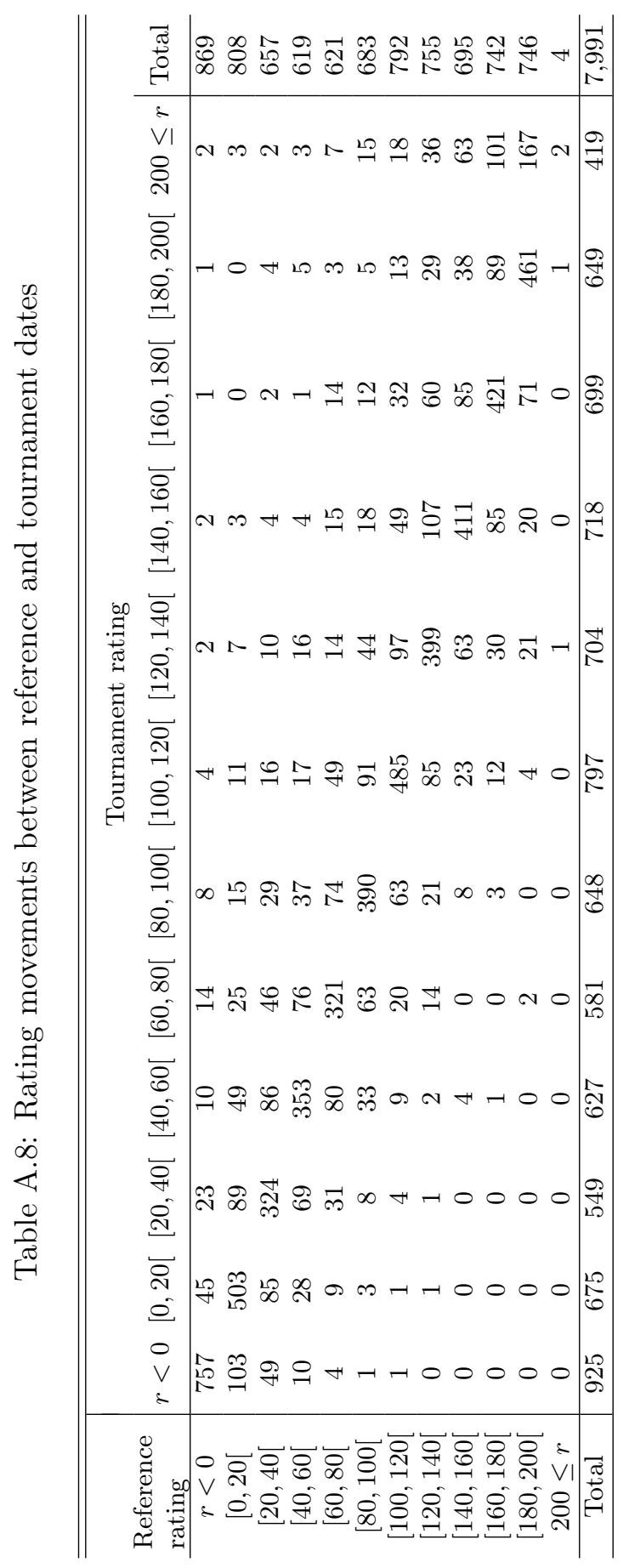




\section{A.3 Proof of Proposition 2}

We have

$$
\begin{aligned}
\frac{d \widehat{\varepsilon}(r)}{d r} & =\int_{\underline{u}}^{\bar{u}}\left[\omega(u, r) \frac{\partial \widehat{\varepsilon}(u, r)}{\partial r}+\frac{\partial \omega(u, r)}{\partial r} \widehat{\varepsilon}(u, r)\right] \psi(u) d u \\
& =\int_{\underline{u}}^{\bar{u}} \frac{\partial \widehat{\varepsilon}(u, r)}{\partial r} \omega(u, r) \psi(u) d u+\int_{\underline{u}}^{\bar{u}}\left[\frac{\partial \omega(u, r)}{\partial r} \widehat{\varepsilon}(u, r)\right] \psi(u) d u \\
& =\mathbb{E}\left[\frac{\partial \widehat{\varepsilon}(u, r)}{\partial r} \mid p=1\right]+\int_{\underline{u}}^{\bar{u}}\left[\frac{\partial \omega(u, r)}{\partial r} \widehat{\varepsilon}(u, r)\right] \psi(u) d u .
\end{aligned}
$$

We now compute $\frac{\partial \omega(u, r)}{\partial r}$. Using that $\frac{\partial \widetilde{\varepsilon}(u, r)}{\partial r}=-1$ we have

$$
\begin{aligned}
\frac{\partial \omega(u, r)}{\partial r} & =\frac{\phi(\widetilde{\varepsilon} \mid u)-\omega(u, r) \int_{\underline{u}}^{\bar{u}} \phi(\widetilde{\varepsilon}) \psi(u) d u}{\int_{\underline{u}}^{\bar{u}}(1-\Phi(\widetilde{\varepsilon} \mid u)) \psi(u) d u}=\left(\frac{\phi(\widetilde{\varepsilon} \mid u)}{1-\Phi(\widetilde{\varepsilon} \mid u)}-\frac{\int_{\underline{u}}^{\bar{u}} \phi(\widetilde{\varepsilon} \mid u) \psi(u) d u}{\int_{\underline{u}}^{\bar{u}}(1-\Phi(\widetilde{\varepsilon} \mid u)) \psi(u) d u}\right) \omega(u, r) \\
& =\left(h(\widetilde{\varepsilon} \mid u)-\int_{\underline{u}}^{\bar{u}} h(\widetilde{\varepsilon} \mid u) \frac{(1-\Phi(\widetilde{\varepsilon} \mid u)) \psi(u)}{\int_{\underline{u}}^{\bar{u}}(1-\Phi(\widetilde{\varepsilon} \mid u)) \psi(u) d u} d u\right) \omega(u, r) \\
& =\left(h(\widetilde{\varepsilon} \mid u)-\int_{\underline{u}}^{\bar{u}} h(\widetilde{\varepsilon} \mid u) \omega \psi(u) d u\right) \omega(u, r)=(h(\widetilde{\varepsilon} \mid u)-\mathbb{E}[h(\widetilde{\varepsilon} \mid u) \mid p=1]) \omega(u, r) .
\end{aligned}
$$

Therefore

$$
\begin{aligned}
\int_{\underline{u}}^{\bar{u}}\left[\frac{\partial \omega(u, r)}{\partial r} \widehat{\varepsilon}(u, r)\right] \psi(u) d u & =\int_{\underline{u}}^{\bar{u}}(h(\widetilde{\varepsilon} \mid u)-\mathbb{E}[h(\widetilde{\varepsilon} \mid u) \mid p=1]) \widehat{\varepsilon}(u, r) \omega(u, r) \psi(u) d u \\
& =\operatorname{Cov}[h(\widetilde{\varepsilon} \mid u), \widehat{\varepsilon}(u, r) \mid p=1],
\end{aligned}
$$

which gives equation (4) in Proposition 2. To obtain equation (5) we use that (see the proof of Lemma 1)

$$
\frac{\partial \widehat{\varepsilon}(u, r)}{\partial r}=-h(\widetilde{\varepsilon} \mid u)[\widehat{\varepsilon}(u, r)-\widetilde{\varepsilon}] .
$$

Then $\mathbb{E}\left[\frac{\partial \widehat{\varepsilon}(u, r)}{\partial r} \mid p=1\right]$ writes

$$
\begin{aligned}
\int_{\underline{u}}^{\bar{u}} \frac{\partial \widehat{\varepsilon}(u, r)}{\partial r} \omega(u, r) \psi(u) d u= & -\int_{\underline{u}}^{\bar{u}} h(\widetilde{\varepsilon} \mid u)[\widehat{\varepsilon}(u, r)-\widetilde{\varepsilon}] \omega(u, r) \psi(u) d u \\
= & -\operatorname{Cov}[h(\widetilde{\varepsilon} \mid u),(\widehat{\varepsilon}(u, r)-\widetilde{\varepsilon}) \mid p=1]-\mathbb{E}[h(\widetilde{\varepsilon} \mid u) \mid p=1] \mathbb{E}[\widehat{\varepsilon}(u, r)-\widetilde{\varepsilon} \mid p=1] \\
= & -\operatorname{Cov}[h(\widetilde{\varepsilon} \mid u), \widehat{\varepsilon}(u, r) \mid p=1]+\operatorname{Cov}[h(\widetilde{\varepsilon} \mid u), \widetilde{\varepsilon}(u, r) \mid p=1] \\
& -\mathbb{E}[h(\widetilde{\varepsilon} \mid u) \mid p=1] \mathbb{E}[\widehat{\varepsilon}(u, r)-\widetilde{\varepsilon} \mid p=1]
\end{aligned}
$$

and expression (5) of Proposition 2 follows.

Proof of the sufficient conditions:

i. Under independence of $\varepsilon$ and $u$ it follows that $\widehat{\varepsilon}(u, r) \searrow$ with $u$ (the proof is similar to the one of Lemma 1). Under the additional assumption that $h(\varepsilon \mid u) \searrow$ with $\varepsilon$ it also follows that $h(\widetilde{\varepsilon} \mid u) \nearrow$ with $u$. We then have $\operatorname{Cov}[h(\widetilde{\varepsilon} \mid u), \widetilde{\varepsilon}(u, r) \mid p=1]<0$. 
To verify that the four remaining conditions are also sufficient for $\frac{d \widehat{\varepsilon}(r)}{d r} \leq 0$, we verify that they guarantee that $h(\widetilde{\varepsilon} \mid u)$ is non-decreasing with $u$. If indeed this hazard is a nondecreasing function of $u$, the covariance term appearing in (5), $\operatorname{Cov}[h(\widetilde{\varepsilon} \mid u), \widetilde{\varepsilon}(u, r) \mid p=1]$, is negative (since $\widetilde{\varepsilon}(u, r)$ is always decreasing with $u$ : $\partial \widetilde{\varepsilon} / \partial u=-1 / g(r+\widetilde{\varepsilon})<0$ ), which is a sufficient condition for $\frac{d \widehat{\varepsilon}(r)}{d r} \leq 0$.

The total derivative of $h(\widetilde{\varepsilon} \mid u)$ is

$$
\frac{d h(\widetilde{\varepsilon} \mid u)}{d u}=\frac{\partial \widetilde{\varepsilon}}{\partial u} \frac{\partial h(\widetilde{\varepsilon} \mid u)}{\partial \varepsilon}+\frac{\partial h(\widetilde{\varepsilon} \mid u)}{\partial u} .
$$

Replacing $\frac{\partial \widetilde{\varepsilon}}{\partial u}$ by $-1 / g(r+\widetilde{\varepsilon})<0$, the sign of the derivative of $h(\widetilde{\varepsilon} \mid u)$ depends on the following conditions:

$$
\frac{d h(\widetilde{\varepsilon} \mid u)}{d u} \geq 0 \Leftrightarrow \begin{cases}\frac{\partial h(\widetilde{\varepsilon} \mid u) / \partial u}{\partial h(\widetilde{\varepsilon}) / \partial \varepsilon} \geq \frac{1}{g(r+\widetilde{\varepsilon})} & \text { if } \partial h(\widetilde{\varepsilon} \mid u) / \partial \varepsilon>0 \\ \frac{\partial h(\widetilde{\varepsilon} \mid u) / \partial u}{\partial h(\widetilde{\varepsilon} \mid u) / \partial \varepsilon} \leq \frac{1}{g(r+\widetilde{\varepsilon})} & \text { if } \partial h(\widetilde{\varepsilon} \mid u) / \partial \varepsilon<0 \\ \partial h(\widetilde{\varepsilon} \mid u) / \partial u \geq 0 & \text { if } \partial h(\widetilde{\varepsilon} \mid u) / \partial \varepsilon=0\end{cases}
$$

ii. When $h(\widetilde{\varepsilon} \mid u) \nearrow$ with $u$ and $h(\widetilde{\varepsilon} \mid u) \searrow$ with $\varepsilon$, then $\frac{d h(\widetilde{\varepsilon} \mid u)}{d u}>0$ because of equation (12).

iii. The hazard rate is independent of $\varepsilon$ and is written $h(\varepsilon \mid u)=\lambda(u)$. When in addition $\lambda(u) \nearrow$ with $u$, then $\frac{d h(\widetilde{\varepsilon} \mid u)}{d u}>0$ because of equation (12).

iv. When $h(\widetilde{\varepsilon} \mid u) \nearrow$ with $u$ and $h(\widetilde{\varepsilon} \mid u) \nearrow$ with $\varepsilon$, and $\frac{\partial h(\widetilde{\varepsilon} \mid u) / \partial u}{\partial h(\widetilde{\varepsilon} \mid u) / \partial \varepsilon} \geq \frac{1}{g(r+\widetilde{\varepsilon})}$, then $\frac{d h(\widetilde{\varepsilon} \mid u)}{d u} \geq 0$ because of equation (13).

v. When $h(\widetilde{\varepsilon} \mid u) \nearrow$ with $u$ and $h(\widetilde{\varepsilon} \mid u) \searrow$ with $\varepsilon$, and $\frac{\partial h(\widetilde{\varepsilon} \mid u) / \partial u}{\partial h(\widetilde{\varepsilon} \mid u) / \partial \varepsilon} \leq \frac{1}{g(r+\widetilde{\varepsilon})}$, then $\frac{d h(\widetilde{\varepsilon} \mid u)}{d u} \geq 0$ because of equation (13). 